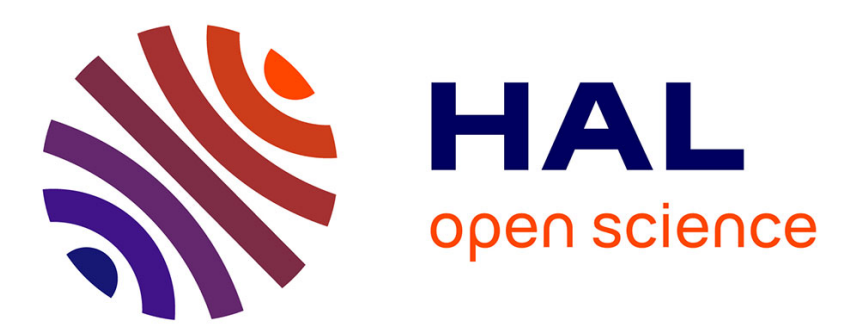

\title{
New kinetic model of the dehydration reaction of magnesium sulfate hexahydrate: Application for heat storage
}

Larysa Okhrimenko, Loïc Favergeon, Kevyn Johannes, Frédéric Kuznik

\section{- To cite this version:}

Larysa Okhrimenko, Loïc Favergeon, Kevyn Johannes, Frédéric Kuznik. New kinetic model of the dehydration reaction of magnesium sulfate hexahydrate: Application for heat storage. Thermochimica Acta, 2020, 687, pp.178569. emse-02972906

\section{HAL Id: emse-02972906 \\ https://hal-emse.ccsd.cnrs.fr/emse-02972906}

Submitted on 20 Oct 2020

HAL is a multi-disciplinary open access archive for the deposit and dissemination of scientific research documents, whether they are published or not. The documents may come from teaching and research institutions in France or abroad, or from public or private research centers.
L'archive ouverte pluridisciplinaire HAL, est destinée au dépôt et à la diffusion de documents scientifiques de niveau recherche, publiés ou non, émanant des établissements d'enseignement et de recherche français ou étrangers, des laboratoires publics ou privés. 


\title{
New kinetic model of the dehydration reaction of magnesium sulfate hexahydrate: application for heat storage
}

\author{
Larysa Okhrimenko ${ }^{\mathrm{a}, \mathrm{b}, \mathrm{c}}$, Loïc Favergeon ${ }^{\mathrm{a}, *}$, Kévyn Johannes $^{\mathrm{b}, \mathrm{c}}$, Frédéric Kuznik ${ }^{\mathrm{c}}$
}

a Mines Saint-Etienne, Université de Lyon, CNRS UMR5307 LGF, F-42023 Saint-Etienne, France

${ }^{\mathrm{b}}$ Université de Lyon, Université Lyon 1, CETHIL UMR5008, F-69622 Villeurbanne, France

${ }^{c}$ Université de Lyon, INSA-Lyon, CETHIL UMR5008, F-69621 Villeurbanne, France

favergeon@emse.fr

\begin{abstract}
Magnesium sulfate-water vapor is an interesting working pair of thermochemical materials for compact inter-seasonal heat storage at low temperature. Total dehydration of magnesium sulfate heptahydrate shows a theoretical storage energy density of $2.8 \mathrm{GJ} \cdot \mathrm{m}^{-3}$. However, kinetic data are poorly studied up to now making use of this material difficult for a practical storage application. In the present work, a kinetic study of the dehydration of $\mathrm{MgSO}_{4} \cdot 6 \mathrm{H}_{2} \mathrm{O}$ powder at low temperature (35 to $60^{\circ} \mathrm{C}$ ) and at low water vapor pressure $(2$ to $21 \mathrm{hPa}$ ) is carried out using thermogravimetric analysis in isobaric-isothermal conditions. A mathematical model is developed for this bivariant system and validated representing the mechanism of dehydration: water molecules diffusion in the solid solution followed by transfer of these molecules from the surface to the atmosphere. The transfer of water molecules at the surface during dehydration is identified as rate-determining step. The fractional conversion and reaction rate of the dehydration reaction are calculated and compared to the experimental data.
\end{abstract}

\section{Introduction}

Price increasing of fossil fuel sources owing to their unavoidable depletion, the steady augmentation of energy demand and the global warming have already steered research toward decentralized renewable energy and a more efficient energy use. Renewable energy systems based on capturing solar radiation are identified as promising sources enabling to decrease fossil energy consumption and greenhouse gas emissions. However, due to the intermittent character of the solar energy (characterized by both daily and seasonally shift between the supply and the energy demand), the development of energy storage systems is required for matching production and demand. This shift is mandatory to valorize the excess solar energy obtained during summer in order use it during winter: this is seasonal, long-term, heat storage $[1,2]$. Among the various processes to store heat, thermochemical heat storage materials appears to be promising for the heat storage application due to their high energy storage capacities and low heat losses during the storage time [3-6]. Salt 
hydrates have a high theoretical energy density, dehydration temperature that can be provided by solar thermal collectors and hydration temperatures useful for building heating and domestic hot water supply. Among different hydrated salts, magnesium sulfate hydrate is presented as one of the best potential heat storage material [4,7-11]. The whole reaction leading from $\mathrm{MgSO}_{4} \cdot 7 \mathrm{H}_{2} \mathrm{O}$ to anhydrous $\mathrm{MgSO}_{4}$ presents a theoretical storage energy density of $2.8 \mathrm{GJ} \cdot \mathrm{m}^{-3}$. However, complete dehydration under suitable operating conditions is impossible; formation of anhydrous $\mathrm{MgSO}_{4}$ carries out at high temperature $\left(>150^{\circ} \mathrm{C}\right)$. In fact the most important part of this energy density is due to the dehydration reaction of $\mathrm{MgSO}_{4} \cdot 6 \mathrm{H}_{2} \mathrm{O}$ toward a lower hydrate. For example, Van Essen et al. [12] have reported experimental value of $2.2 \mathrm{GJ} \cdot \mathrm{m}^{-3}$ during the transition from $\mathrm{MgSO}_{4} \cdot 6 \mathrm{H}_{2} \mathrm{O}$ to $\mathrm{MgSO}_{4} \cdot 0.1 \mathrm{H}_{2} \mathrm{O}$ and Ferchaud et al. [13] measured $1.69 \mathrm{GJ} \cdot \mathrm{m}^{-3}$ for the transition from $\mathrm{MgSO}_{4} \cdot 6 \mathrm{H}_{2} \mathrm{O}$ to $\mathrm{MgSO}_{4} \cdot 1 \mathrm{H}_{2} \mathrm{O}$. In order to overcome this issue, new composite materials were developed where salt hydrates are embedded inside a porous matrix. Since the salt crystal of small size is dispersed within the porous structure, the problem of agglomeration is limited and both heat and mass transfer in the granular medium remain efficient, leading to an improvement of the material lifetime. The use of active porous matrix such as silica gel, zeolite, MOFs, etc... allows to benefit from the heat produced by the chemical reaction on the hygroscopic salt and by the adsorption on the porous material [14-25]. Nevertheless, the development of such a system remains a technological challenge, the main obstacle being the incomplete understanding of the involved physicochemical phenomena. If different porous systems are quite well investigated, kinetic behavior of both dehydration and hydration reactions occurring in the $\mathrm{MgSO}_{4}-\mathrm{H}_{2} \mathrm{O}$ system remains poorly understood up to now. In previous studies, researchers have investigated dehydration/hydration reaction at the grain scale using thermogravimetric analysis, differential scanning calorimetry, in-situ X-ray diffraction, scanning electron microscopy, spectroscopy RAMAN and Nuclear Magnetic Resonance $[12,13,15,26-30]$. The dehydration of $\mathrm{MgSO}_{4} \cdot 7 \mathrm{H}_{2} \mathrm{O}$ under heat storage conditions involves trees steps: i) the formation of magnesium sulfate hexahydrate, ii) the formation of magnesium sulfate monohydrate, and finally iii) the formation of anhydrous magnesium sulfate. Those phases are known as natural stable minerals. Other metastable hydrates $\mathrm{MgSO}_{4} \cdot \mathrm{xH}_{2} \mathrm{O}$ have been determined in the literature where $x=11,5,4,3,2.4,2$ and 5/4. Pentahydrate, tetrahydrate, and dihydrate of magnesium sulfate have been observed as efflorescent salts in some mines where sulfides are located under specific humid conditions [31]. Other authors obtained various hydrates synthetically under several conditions by using the humidity buffer technique or by evaporation of an aqueous solution of $\mathrm{MgSO}_{4}$ [31-36]. The interaction with water or water vapor plays an important role in the formation of hydrates. The formation of the pure crystalline phase of $\mathrm{MgSO}_{4} \cdot 1 \mathrm{H}_{2} \mathrm{O}$ by dehydration is very difficult. Dehydration of $\mathrm{MgSO}_{4} \cdot 6 \mathrm{H}_{2} \mathrm{O}$ in order to obtain monohydrate leads to the formation of amorphous phase which can contain various water content, sometimes presented as a mixture of different phases of magnesium sulfate [32,37,38]. Non-stoichiometric hydrates with 1.3, 1.18 and $1.09 \mathrm{~mol} \mathrm{H}_{2} \mathrm{O}$ per $\mathrm{mol} \mathrm{MgSO}_{4}$ have been identified by gravimetric measurements of dehydration. Many authors have observed lower non-stoichiometric hydrates with $0.1,0.2$ and $0.3 \mathrm{~mol}_{2} \mathrm{O}$ per mol $\mathrm{MgSO}_{4}$ by dehydration of $\mathrm{MgSO}_{4} \cdot 6 \mathrm{H}_{2} \mathrm{O}$ in non-isothermal conditions and under dry or wet $\mathrm{N}_{2}$ atmospheres in a temperature range between 250 and $275^{\circ} \mathrm{C}[12,14-16,39]$.

It has been demonstrated that the $\mathrm{MgSO}_{4} / \mathrm{H}_{2} \mathrm{O}$ system is bivariant during the dehydration process from magnesium sulfate hexahydrate at low temperature $\left(35-80^{\circ} \mathrm{C}\right)$ and low water vapor pressure $\left(10^{-3}-7 \mathrm{hPa}\right)$ and some hydrates appear as non-stoichiometric hydrates as demonstrated in our previous paper [28]. Compared to stoichiometric hydrates which correspond to a specific 
composition and to monovariant system, non-stoichiometric hydrates are those with continuously variable composition within a certain range, without any significant corresponding change in the crystal structure [40]. Any known metastable phases have been observed by dehydration at these conditions. Such behavior has been reported for pharmaceutical hydrates [41,42], hydrated ytterbium nitrate [43], $\mathrm{WO}_{3}-\mathrm{H}_{2} \mathrm{O}$ system [44] or hydrated pyrochlore $\mathrm{NaW}_{2} \mathrm{O}_{6} \cdot \mathrm{nH}_{2} \mathrm{O}$ [45] for example.

The dehydration kinetic of high hydrates of magnesium sulfate was poorly investigated up to now. From previous studies, it is just evident that the overall kinetic of the dehydration reaction depends on temperature, water vapor pressure, sample size and number of cycle $[27,46,47]$. However, up to now, the understanding of reaction mechanism or kinetic model of dehydration reaction is not available. For the heat energy storage application, the dehydration reaction occurs at high temperature, i.e. $60^{\circ} \mathrm{C}[48-50]$. In these high temperature conditions, the chemical kinetics of the reaction is very important at the laboratory scale since only a small amount of powder must be used [51-53]. As the purpose of the present paper is to study the kinetic of dehydration of magnesium sulfate hexahydrate and to understand the mechanism for this reaction, it is necessary to slow down the reaction; therefore the study is performed at low temperature and low water vapor pressure.

As a consequence this reaction can be written as follow:

$\mathrm{MgSO}_{4} \cdot 6 \mathrm{H}_{2} \mathrm{O}=\mathrm{MgSO}_{4} \cdot \varepsilon \mathrm{H}_{2} \mathrm{O}+(6-\varepsilon) \mathrm{H}_{2} \mathrm{O}$

where $\varepsilon$ represents the water constant in the solid phase defined as the total quantity of water remaining in the solid phase per mol of magnesium sulfate.

As the magnesium sulfate/water vapor system is a bivariant system at low temperatures and low water vapor pressures conditions, it implies that the final product of the dehydration reaction is a continuous function of the temperature and water vapor pressure. Thus the definition of a classical fractional conversion, given for example by the ICTAC Kinetics Committee [51], appears to be inappropriate for this system. The conventional kinetic modeling approaches such as model fitting or isoconversional methods are based on the steady-state assumption which allows to define a fractional conversion ranging from 0 to 1 in all the thermodynamic domain of study. In the present work we propose to check the non steady-state behavior of the reaction and to investigate the reaction mechanism of dehydration process in this bivariant system and finally the developed kinetic model will be compared to TG results.

\section{Materials and methods}

\subsection{Sample preparation and characterization}

Magnesium sulfate hexahydrate, used as starting material, was obtained by in situ dehydration of beforehand crushed commercial magnesium sulfate heptahydrate (VWR BDH Prolabo, CAS 1003499-8, NORMAPUR, $99.5 \%$ pure) at $40{ }^{\circ} \mathrm{C}$ and $25 \mathrm{hPa}$. X-ray powder diffraction (XRD) patterns were recorded using a Siemens $\mathrm{D} 5000$ diffractometer operating with monochromatic $\mathrm{Cu}-\mathrm{K} \alpha$ radiation $(\lambda$ $=1.54 \AA$ ). . The XRD patterns were scanned in the $2 \Theta$ range from 10 to $60^{\circ}$ with an angular step size of $0.02^{\circ}$ and a scan time of $5 \mathrm{~s}$. Textural properties of the magnesium sulfate hexahydrate were determined by means of nitrogen adsorption measurements performed using a micromeritics 2020 analyzer. Scanning electron microscope (SEM) JEOL FEG 6500 (apparatus operating at 15kV) was 
used to characterize both the morphology and the size of the initial powder. The particle size distribution was also evaluated by means of laser diffraction measurements performed on a Mastersizer 2000 from Malvern-Panalytical using a dry sampling system and a suitable procedure (refractive index of $\mathrm{MgSO}_{4} \cdot 7 \mathrm{H}_{2} \mathrm{O}: 1.433$, measurement time: $30 \mathrm{~s}$, dispersive air pressure: $0.37 \mathrm{MPa}$ ).

\subsection{Characterization of thermal behavior}

Four samples were prepared in order to be characterized. For each sample, approximately $5 \mathrm{mg}$ of the commercial crushed powder was weighted into a quartz crucible and placed at ambient conditions in a symmetrical suspension-type TGA instrument (SETARAM MTB $10^{-8}$ ) within static conditions. Thermoregulated water baths were used to fix and kept constant the water vapor pressure, i.e. the water pressure is equal to the liquid/vapor equilibrium of pure water at a given temperature [54]. The first water bath is regulated at $16^{\circ} \mathrm{C}$ which corresponds to a water vapor pressure of $18 \mathrm{hPa}$. After the introduction of the sample in the thermobalance, vacuum (about $10^{-3}$ $\mathrm{hPa}$ ) was performed in the system by pumping for about $30 \mathrm{~s}$. The first water bath is then connected to the sample chamber which is kept at $20^{\circ} \mathrm{C}$. The sample is thus kept at $20^{\circ} \mathrm{C}$ and $\mathrm{P}\left(\mathrm{H}_{2} \mathrm{O}\right)=18 \mathrm{hPa}$ during one hour. Another water bath is kept at $-14.5^{\circ} \mathrm{C}$ which corresponds to a water vapor pressure of $2 \mathrm{hPa}$.

For the first sample, called S1, the powder was removed from the thermobalance after one hour at $\mathrm{T}=20^{\circ} \mathrm{C}$ and $\mathrm{P}_{\mathrm{H} 2 \mathrm{O}}=25 \mathrm{hPa}$. For the sample S2, after one hour at $\mathrm{T}=20^{\circ} \mathrm{C}$ and $\mathrm{P}_{\mathrm{H} 2 \mathrm{O}}=25 \mathrm{hPa}$, the temperature was increased up to $40^{\circ} \mathrm{C}$ and kept constant during one hour. Concerning the sample $\mathrm{S} 3$, the protocol was similar to that for $\mathrm{S} 2$, then the water vapor pressure was decreased by pumping and then kept constant at $2 \mathrm{hPa}$. Once the mass was stabilized, the powder was removed from the thermobalance. Finally the last sample called S4 was obtained with the same protocol as S2 followed by one hour at $350^{\circ} \mathrm{C}$ under dry $\mathrm{N}_{2}$.

Phase diagram of magnesium sulfate hydrates is shown in Fig. 1. The thermodynamic data for the equilibrium and deliquescence curves are extracted from Steiger et al. [14] and the bivariant domain represented by the shaded area arises out of our previous work [28]. The black solid line represents the water vapor saturation line. The violet, red and grey solid lines represent equilibrium transition between $\mathrm{MgSO}_{4} \cdot 7 \mathrm{H}_{2} \mathrm{O}-\mathrm{MgSO}_{4} \cdot 6 \mathrm{H}_{2} \mathrm{O}, \mathrm{MgSO}_{4} \cdot 6 \mathrm{H}_{2} \mathrm{O}-\mathrm{MgSO}_{4} \cdot 1 \mathrm{H}_{2} \mathrm{O}$ and $\mathrm{MgSO}_{4} \cdot 7 \mathrm{H}_{2} \mathrm{O}-\mathrm{MgSO}_{4} \cdot 1 \mathrm{H}_{2} \mathrm{O}$, respectively. The green and blue dashed lines correspond to deliquescence humidities of magnesium sulfate heptahydrate and magnesium sulfate hexahydrate respectively. According to the thermodynamic $\mathrm{P}(\mathrm{T})$ diagram of Fig. 1, samples $\mathrm{S} 1$ should correspond to highly hydrated magnesium sulfate with a general formula $\mathrm{MgSO}_{4} \cdot 7 \mathrm{H}_{2} \mathrm{O}, \mathrm{S} 3$ and $\mathrm{S} 4$ should belong to the bivariant region between mono- and hexahydrate, and to the stability domain of anhydrous magnesium sulfate, respectively. Even if sample S2 appears to be out of the thermodynamic stability domain of magnesium sulfate hexahydrate, it has been observed by Steiger [34] and Wang [32] that $\mathrm{MgSO}_{4} \cdot 6 \mathrm{H}_{2} \mathrm{O}$ does not dehydrate even if the temperature and water vapor pressure conditions correspond to stability domain to lower hydrates. The authors concluded that the dehydration kinetics of magnesium sulfate hexahydrate is very low in these conditions. In our experimental conditions for sample S2, i.e. $40^{\circ} \mathrm{C}$ and $\mathrm{P}\left(\mathrm{H}_{2} \mathrm{O}\right)=25 \mathrm{hPa}$ for one hour, no change in mass or in phase composition was observed which is in agreement with the conclusions of Steiger et al. 


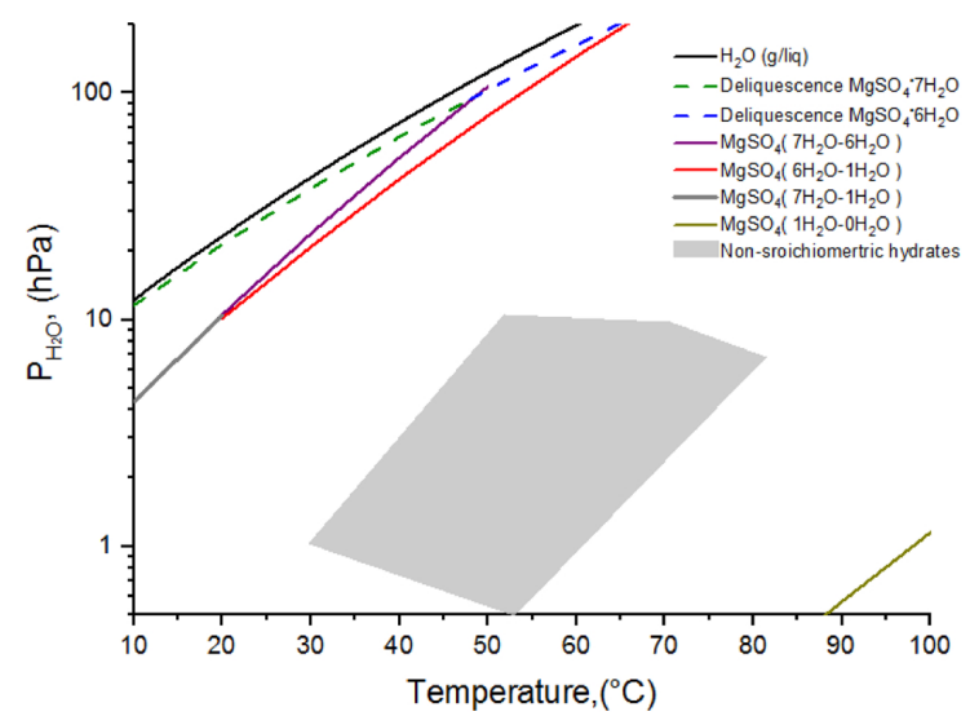

Fig. 1. Phase diagram $P_{\mathrm{H}_{2} \mathrm{O}}(T)$ of $\mathrm{MgSO}_{4}-\mathrm{H}_{2} \mathrm{O}$ system, extracted from [28,34].

\subsection{Kinetic measurements}

All dehydration experiments were carried out at constant temperature $(T)$ and pure water vapor pressure $\left(\mathrm{P}_{\mathrm{H} 2 \mathrm{O}}\right)$ using the symmetrical suspension-type thermobalance (MTB10-8 from SETARAM) in static conditions as described in section 2.2.

The thermogravimetric experiments were realized in isothermal and isobaric conditions and the dehydration procedure was the same for each experiment. Preliminary measurements for different initial sample masses $m_{0}$ with the same temperature $\left(50^{\circ} \mathrm{C}\right)$ and water vapor pressure $(2 \mathrm{hPa})$ were performed in order to determine the maximal sample mass to use to avoid both heat and pressure gradients in the powder layer during the reaction. Fig. 2 exhibits two features:

(i) regardless of the initial sample mass, the sample mass continuously decreases versus time up to its stabilization. This indicates that the reaction reached an equilibrium state. As discussed in [28], this equilibrium state is a function of both the temperature and the water vapor pressure imposed during the experiment, and does not correspond to a stoichiometric compound. Such a behavior has been reported for the thermal dehydration of acid barium oxalate [55] and thermal dehydration of $\mathrm{Cd}_{2} \mathrm{Zr}\left(\mathrm{C}_{2} \mathrm{O}_{4}\right)_{4} \cdot(4+\mathrm{n}) \mathrm{H}_{2} \mathrm{O}$ [56]. In both cases the authors have investigated the crystal structures of the solid and have concluded that the water content inside the material depends on both the water vapor pressure and the temperature according to a divariant system and that the corresponding water molecules can then be considered as zeolitic water;

(ii) the mass loss curves obtained with $\mathrm{m}_{0}$ equal to 11 and $5 \mathrm{mg}$ exhibit longer reaction time whereas those with initial sample mass in the range 2.5-3.8 mg are identical. Hence, for each experiment a sample of crushed powder of about $3 \mathrm{mg}$ was weighted in a quartz crucible $(12 \mathrm{~mm}$ in diameter and $8 \mathrm{~mm}$ in height). This sample weight was sufficiently low to cover uniformly the crucible bottom without formation of think powder layer. Thus, mass and heat transfer phenomena are fast in the powder layer and all particles can be considered in the same temperature and water vapor pressure conditions [51]. The accuracy of the thermobalance is about $0.001 \mathrm{mg}$, which allows the measurement of the mass change to be carried out properly. 


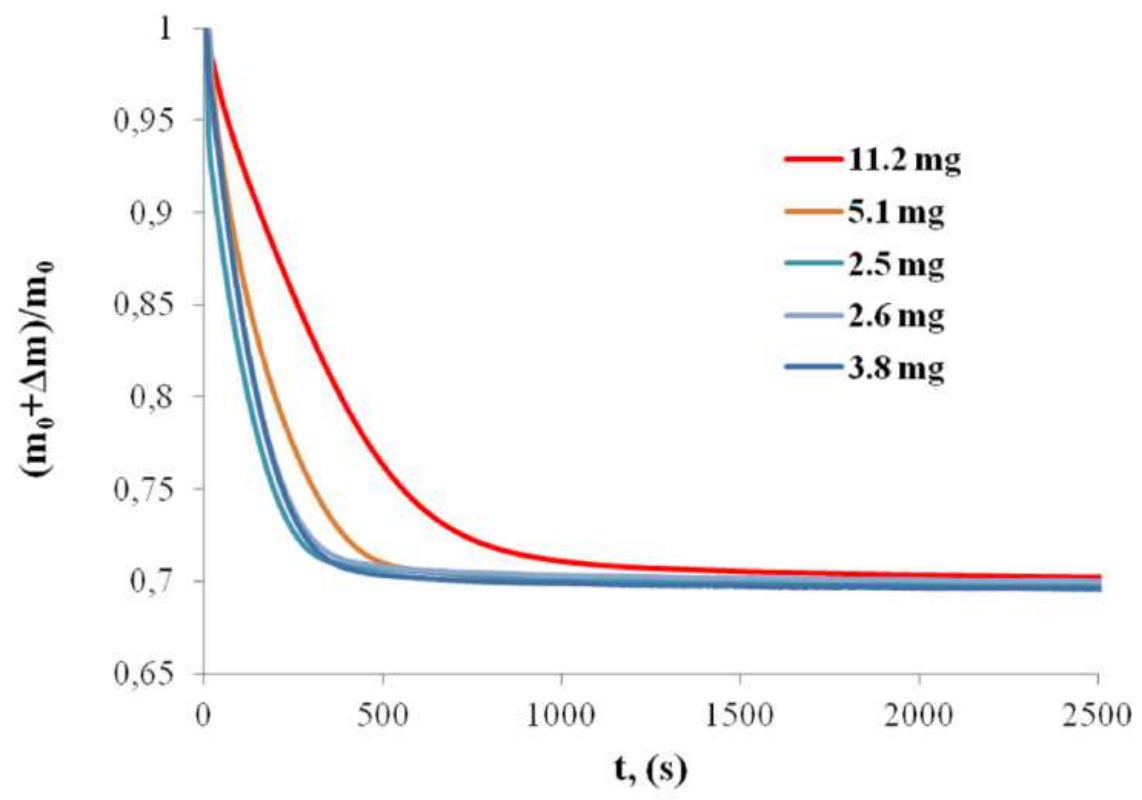

Fig. 2. Mass loss versus time for $\mathrm{MgSO}_{4} \cdot 6 \mathrm{H}_{2} \mathrm{O}$ dehydration at $50{ }^{\circ} \mathrm{C}$ and $2 \mathrm{hPa}$ with various initial sample masses.

The dehydration experiments consist in two consecutive steps, since the starting material is magnesium sulfate heptahydrate:

(a) after introduction of the sample in the furnace of the thermobalance at ambient conditions, vacuum (about 10-3 hPa) was performed in the system for about $30 \mathrm{~s}$ and then water vapor pressure has been raised to $18 \mathrm{hPa}$ in order to stabilize the sample mass of magnesium sulfate heptahydrate phase. After mass stabilization at this pressure during $15 \mathrm{~min}$, the first dehydration step was performed thanks to increase both the temperature to a given value between 40 and $60^{\circ} \mathrm{C}$ and the water vapor pressure to a value between 25 and $100 \mathrm{hPa}$. The choice of water vapor pressure depends on equilibrium temperature for the purpose of avoiding water condensation in the system and placing the sample into conditions of magnesium sulfate hexahydrate formation. Experimental mass loss of the first dehydration reaction has been measured at about $7.2 \pm 0.3 \%$ for all the experiments. This value corresponds correctly to the theoretical mass loss equal to $7.3 \%$ when considering the dehydration reaction from magnesium sulfate heptahydrate $\left(\mathrm{MgSO}_{4} \cdot 7 \mathrm{H}_{2} \mathrm{O}\right)$ to magnesium sulfate hexahydrate $\left(\mathrm{MgSO}_{4} \cdot 6 \mathrm{H}_{2} \mathrm{O}\right)$.

lb) once the mass signal was stabilized, the second step of dehydration was performed by decreasing the water vapor pressure to a chosen value in the range $2 \mathrm{hPa}$ to $50 \mathrm{hPa}$. The change of the water vapor pressure was achieved by short pumping and then pressure was maintained constant with the help of the thermoregulated water bath. It takes less than $30 \mathrm{~s}$ to decrease the pressure from the high value and to stabilize to the pressure of experiment. The mass change during the second step of dehydration reaction was thus recorded in isothermal and isobaric conditions. In order to ensure the reliability of the obtained results, several experiments were repeated in the same conditions and it was highlighted an excellent repeatability in isothermal and isobaric conditions. According to the chemical reaction (1), the mass change measured by thermogravimetry can be expressed into a fractional conversion $\alpha \varepsilon$ for each non-stoichiometric hydrate obtained at the given temperature and water vapor pressure. This fractional conversion $\alpha \varepsilon$ is calculated by: 


$$
\alpha_{\varepsilon}=\frac{m_{t}-m_{0}}{m_{f}-m_{0}}=\frac{m_{t}-m_{0}}{\Delta m_{\mathrm{th}}}
$$

where $m_{t}$ is the sample mass at time $t, m_{0}$ is the initial sample mass, $m_{f}$ is the final sample mass and $\Delta m_{\text {th }}$ is the theoretical mass variation according to equation (1) and can be calculated by Eq. (3):

$$
\Delta m_{\mathrm{th}}=\frac{m_{0}}{M_{\mathrm{MgSO}_{4} \cdot \mathrm{H}_{2} \mathrm{O}} \varepsilon M_{6 \mathrm{H}_{2} \mathrm{O}}}
$$

where $\mathrm{M}_{\mathrm{MgSO4} \cdot 6 \mathrm{H} 2 \mathrm{O}}$ is the molar mass magnesium sulfate hexahydrate $\left(228 \mathrm{~g} \cdot \mathrm{mol}^{-1}\right), \mathrm{M}_{\mathrm{H} 2 \mathrm{O}}$ is the molar mass of water $\left(18 \mathrm{~g} \cdot \mathrm{mol}^{-1}\right)$ and $\varepsilon$ is defined as the total quantity of water remained in the solid per mol of low hydrate salt in specific temperature and water vapor pressure conditions [28].

For investigating the steady-state assumption, TG-DSC measurements were carried out under a stream of wet $\mathrm{N}_{2}$. The sample of approximately $2.0 \mathrm{mg}$ was weighed into a platinum sample crucible (4 $\mathrm{mm}$ in diameter and $10 \mathrm{~mm}$ in height). The weighed sample was set in TG-DSC instrument (Setaram Sensys-Evo) and heated to $40^{\circ} \mathrm{C}$ in a stream of wet $\mathrm{N}_{2}\left(1 \mathrm{l} \cdot \mathrm{h}^{-1}\right)$ with controlled $\mathrm{P}_{\mathrm{H} 2 \mathrm{O}}$ value (25 $\mathrm{hPa}$ ) introduced from the humidity controller (Setaram Wetsys). Then the water vapor pressure is quickly decreased (about $30 \mathrm{~s}$ ) up to a smaller value and the TG-DSC curves were recorded.

\section{Solid-state kinetic modeling: theoretical background}

Thermodynamic phase stability of magnesium sulfate in equilibrium with water vapor has been studied in a controlled environment at low water vapor pressure by means of themogravimetry [28]. It has been shown that the water content in the solid phase of magnesium sulfate is a function of temperature at a given water vapor pressure and a function of water vapor pressure at a given temperature. It has been considered that this system is divariant and the solid phase is a solid solution of water molecules in the magnesium sulfate skeleton. Some magnesium sulfate hydrates appear as non-stoichiometric hydrates which are in equilibrium with the gaseous atmosphere. As a consequence, the dehydration reaction of magnesium sulfate hexahydrate can be described by Eq. (1) and the dehydration reaction corresponds to water molecules diffusion through the magnesium sulfate bulk particle followed by their volatilization from the solid surface to the gaseous atmosphere. Thus, the solid system can be represented by two distinct zones (Fig. 3): a diffusion zone in witch water molecules diffuse through the solid bulk particle to the solid-gas interface with a diffusion coefficient $D_{\mathrm{H} 2 \mathrm{O}}\left(\mathrm{m}^{2} \cdot \mathrm{s}^{-1}\right)$ and a surface zone where water molecules pass through the solidgas interface and then are transferred to the gaseous atmosphere. The second process can be considered as the transfer of water molecules within thin fluid film at the surface with the transfer coefficient at the surface $\mathrm{k}_{\mathrm{H} 2 \mathrm{O}}\left(\mathrm{m} \cdot \mathrm{s}^{-1}\right)$. In both zones, the concentration of water molecules varies as a function of time. 


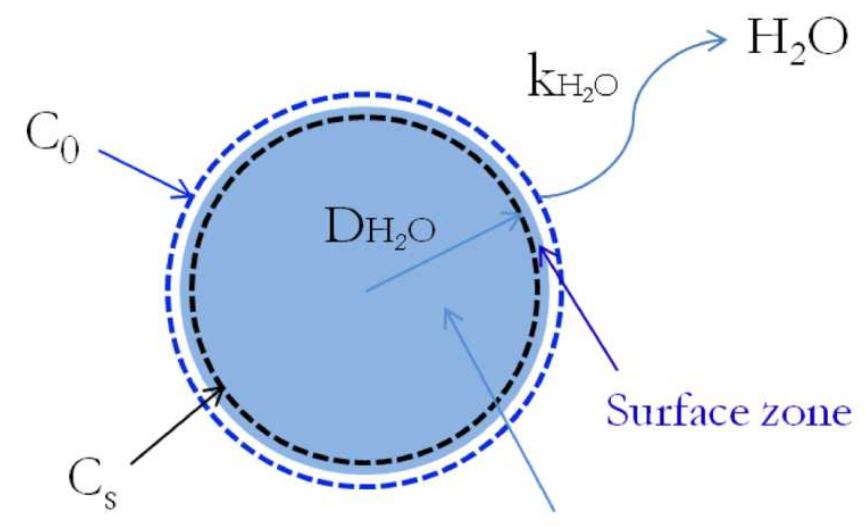

Diffusion zone

Fig. 3. Schematic representation of water departure through the particle of magnesium sulfate hexahydrate during the dehydration reaction.

\section{Fick's laws and diffusion coefficient}

In the case of an ideal solid solution, Fick's first law relates the diffusive flux $\mathrm{J}$ of a diffusive species to the gradient of its concentration $\mathrm{C}$ by the relation:

$$
\vec{J}=-D \overrightarrow{\operatorname{grad} C}
$$

where $D$ is a diffusion coefficient of a diffusive species.

In the case of a non-ideal solid solution, the driving force for diffusion of each species is the gradient of chemical potential of this species [57]. Considering a spherical particle and a one-way diffusion according to the radius direction, Fick's first law can thus be written as:

$$
\vec{J}=-D \frac{C}{\mathrm{RT}} \overrightarrow{\operatorname{grad}} \mu=-D \frac{C}{\mathrm{RT}} \frac{\partial\left(\mu_{0}+\mathrm{RT} \ln a\right)}{\partial r}
$$

where $\mu, \mu_{0}$ and a are the chemical potential, the standard chemical potential and chemical activity of diffusive species respectively, $T$ is the temperature and $R$ is the universal gas constant $(=8.314$ $\left.\mathrm{J} \cdot \mathrm{mol}^{-1} \cdot \mathrm{K}^{-1}\right)$. Considering that the activity of water molecules can be assimilated to the water vapor pressure $\mathrm{P}_{\mathrm{H} 2 \mathrm{O}}$, the diffusive flux J becomes:

$$
\begin{aligned}
\vec{J} & =-D \frac{C}{\mathrm{RT}} \frac{\partial\left(\mu_{0}+\mathrm{RT} \ln P_{\mathrm{H}_{2} \mathrm{O}}\right)}{\partial r}=-D \frac{\partial \ln P_{\mathrm{H}_{2} \mathrm{O}}}{\partial r} \\
& =-D \frac{\partial \ln P_{\mathrm{H}_{2} \mathrm{O}}}{\partial r} \frac{\partial \ln C}{\partial \ln C}=-D \frac{\partial \ln P_{\mathrm{H}_{2} \mathrm{O}}}{\partial \ln C} \frac{\partial C}{\partial r}
\end{aligned}
$$

From equations (4) and (6) the effective diffusion coefficient can be defined as :

$$
D^{*}=D \frac{\partial \ln P_{\mathrm{H}_{2} \mathrm{O}}}{\partial \ln C}
$$


The expression $\partial \mathrm{InP}_{\mathrm{H} 2 \mathrm{O}} / \mathrm{\partial InC}$ corresponds to a so-called "corrected thermodynamic factor" which varies substantially with water vapor molecules concentration and tend to 1 at low concentrations. In the case of an ideal solution, $\mathrm{P}_{\mathrm{H} 2 \mathrm{O}} \sim \mathrm{C}$, the expression $\partial \mathrm{InP}_{\mathrm{H} 2 \mathrm{O}} / \mathrm{\partial lnC}$ is equal to 1 and the effective diffusion coefficient become identical to the Fickian one.

In spherical coordinates, Fick's second law is written:

$$
\frac{\partial C}{\partial t}=D_{\mathrm{H}_{2} \mathrm{O}}\left(\frac{\partial^{2} C}{\partial r^{2}}+\frac{2}{r} \frac{\partial C}{\partial r}\right)
$$

where $\mathrm{C}$ is the concentration of water molecules at time $t, \mathrm{D}_{\mathrm{H} 2 \mathrm{O}}$ is the diffusion coefficient of water molecules in a particle and $r$ is the radius of the particle.

When the initial concentration of water molecules is uniform in the spherical particle, surface condition is given by:

$$
\vec{J}=-D_{\mathrm{H}_{2} \mathrm{O}} \frac{\partial C}{\partial r}=k_{\mathrm{H}_{2} \mathrm{O}}\left(C_{S}-C_{0}\right)
$$

where $C_{0}$ is the concentration of water molecules at the surface, required to be maintained in equilibrium with the surrounding atmosphere, $C_{s}$ is the concentration of water molecules at the surface just within a particle and $\mathrm{k}_{\mathrm{H} 2 \mathrm{O}}$ is the mass transfer coefficient within thin solid film at the surface. The mass transfer coefficient at the surface of the solid corresponds to effective diffusivity $D^{*}$ of water molecules through a thin film with thickness $\delta$ at the surface of a solid particle. The expression of this coefficient is given by: $k_{\mathrm{H} 2 \mathrm{O}}=D^{* / \delta}$.

The required solution of Fick's equation (8) of transfer/diffusion model with initial uniform concentration of water molecules in a spherical particle was proposed by Crank [58]:

$$
\frac{C-C_{0}}{C_{0}-C_{1}}=\frac{2 \mathrm{Lr}_{0}}{r} \sum_{n=1}^{\infty} \frac{\sin \frac{\beta_{n} r}{r_{0}}}{\sin \beta_{n}\left(\beta_{n}^{2}+L(L-1)\right)} \exp \left(-\frac{D_{\mathrm{H}_{2} \mathrm{O}} \beta_{n}^{2} t}{r_{0}^{2}}\right)
$$

In the equation (10), the $\beta \mathrm{n}$ terms are the roots of the follow relation:

$$
\beta_{n} \cot \beta_{n}+L-1=0
$$

The parameter $L$ is the ratio of mass transfer coefficient at the surface of solid by diffusion coefficient of water molecules within a solid multiplied by the radius of a particle $r$ as follow:

$$
L=\frac{\mathrm{rk}_{\mathrm{H}_{2} \mathrm{O}}}{D_{\mathrm{H}_{2} \mathrm{O}}}
$$

\section{Mass loss rate expression}

The fractional conversion $\alpha_{\varepsilon}$ (Eq. (2)) of diffusing substance entering or leaving the sphere can be present as function of time by [58]: 


$$
\alpha_{\varepsilon}=\frac{m_{t}-m_{0}}{m_{f}-m_{0}}=1-\sum_{n=1}^{\infty} \frac{6 L^{2}}{\beta_{n}^{2}\left(\beta_{n}^{2}+L(L-1)\right)} \exp \left(-\frac{D_{H_{2} O} \beta_{n}^{2} t}{r_{0}^{2}}\right)
$$

This equation allows to calculate the fractional conversion of dehydration reaction of magnesium sulfate hexahydrate Eq. (1) considering that two rates of diffusion and transfer process are of the same order of magnitude. Two particulars situations exist and lead to two limit cases:

- while the diffusion is very fast, the transfer within thin fluid film at the surface is rate controlling. In this case, the diffusion coefficient $D$ is larger than the transfer coefficient $k$ and $L \rightarrow 0$ in Eq. (12). As the coefficient $\beta$ is small so the Eq. (11) can be rewritten as: $\beta^{2}=3$ L. Replacing Eq. (13), the fractional conversation of the reaction is:

$$
\alpha_{\varepsilon}=1-\exp \left(-\frac{3 \mathrm{kt}}{r_{0}}\right)
$$

This model is known as the surface resistance control model [57].

- in the other limit while the transfer of molecules at the surface of particles is fast, intra-particle diffusion control the global rate of reaction. The diffusion coefficient $D$ is small and the transfer coefficient $k$ is large. In this case, $L \rightarrow \infty, \beta_{n} \rightarrow n \pi$ and Eq. (13) is given by:

$$
\alpha_{\varepsilon}=1-\sum_{n=1}^{\infty} \frac{6}{\pi^{2} n^{2}} \exp \left(-\frac{D \pi^{2} n^{2} t}{r_{0}^{2}}\right)
$$

The equation of mass loss rate $(\mathrm{d} \Delta \mathrm{m} / \mathrm{dt})$, related to the rate of reaction $\mathrm{d} \alpha / \mathrm{dt}$, is obtained by derivating of Eq. (2) and by expressing the theoretical mass loss using Eq. (3). The expressions of rate reaction for three different cases (mixed case of diffusion-transfer processus, limit case of transfer and limit case of diffusion) are obtained by derivation of Eqs. (13), (14) and (15) respectively. The expression of corresponding mass loss rates for these three cases can be rewritten by:

$$
\begin{aligned}
& \frac{d \Delta m}{\mathrm{dt}}=6 \frac{m_{0}}{M_{\mathrm{MgSO}_{4} \cdot 6 \mathrm{H}_{2} \mathrm{O}}} \varepsilon M_{\mathrm{H}_{2} \mathrm{O}} \sum_{n=1}^{\infty} \frac{6 L^{2} D}{r_{0}^{2}\left(\beta_{n}^{2}+L(L-1)\right)} \exp \left(-\frac{D \beta_{n}^{2} t}{r_{0}^{2}}\right) \\
& \frac{d \Delta m}{\mathrm{dt}}=3 \frac{m_{0}}{M_{\mathrm{MgSO}_{4} \cdot 6 \mathrm{H}_{2} \mathrm{O}}} \varepsilon M_{\mathrm{H}_{2} \mathrm{O}} \frac{k}{r_{0}} \exp \left(-\frac{3 \mathrm{kt}}{r_{0}}\right) \\
& \frac{d \Delta m}{\mathrm{dt}}=6 \frac{m_{0}}{M_{\mathrm{MgSO}_{4} \cdot 6 \mathrm{H}_{2} \mathrm{O}}} \varepsilon M_{\mathrm{H}_{2} \mathrm{O}} \frac{D}{r_{0}^{2}} \exp \left(-\frac{\mathrm{Dn}^{2} \pi^{2} t}{r_{0}^{2}}\right)
\end{aligned}
$$

III. Determination of rate controlling mass transfer process

The simultaneous kinetic parameter estimation was performed under constrained non-linear optimization in Matlab (fminsearch). Used of non-linear solvers consists in minimizing the squared error between simulated and experimental data as follow: 
$\min \left(f_{\mathrm{par}}\right)=\frac{1}{n} \sum_{n=1}^{n}\left(Y_{i, \mathrm{sim}}-Y_{i, \mathrm{exp}}\right)^{2}$

where $\mathrm{Y}_{\mathrm{i} \text {,sim }}$ and $\mathrm{Y}_{\mathrm{i} \text {,exp }}$ are respectively simulated and experimental values referring to $\alpha_{\varepsilon}$ values of Eqs. (13)-(15) and to (d $\Delta \mathrm{m} / \mathrm{dt}$ ) of Eqs. (16)-(18).

At first, the mixed model of diffusion/transfer was tested to study the influence of each process on the kinetic. The fractional conversation as well as the mass loss rate data calculated respectively by Eqs. (13) and (16) are superimposed to the experimental data. The minimizing method allows to determine $D_{\mathrm{H} 2 \mathrm{O}}$ and L parameters. The $k_{\mathrm{H} 2 \mathrm{O}}$ parameter is then calculated from Eq. (12).

\section{Results and discussion}

\subsection{Thermal behavior and characterization}

Commercial magnesium sulfate hydrate powder was analyzed by means of XRD. The diffractogram obtained for this commercial powder is presented in Fig. 4. The experimental diffraction pattern was compared with known patterns of magnesium sulfate heptahydrate JCPDS 36-0419 (blue pics in Fig. 4) and hexahydrate JCPDS 24-0719 (red pics in Fig. 4). The analysis allows to confirm that the major phase is magnesium sulfate hepahydrate as expected but also to highlight the presence of small amount of magnesium sulfate hexahydrate. This confirms that $\mathrm{MgSO}_{4} \cdot 7 \mathrm{H}_{2} \mathrm{O}$ is partially dehydrated under atmospheric conditions.

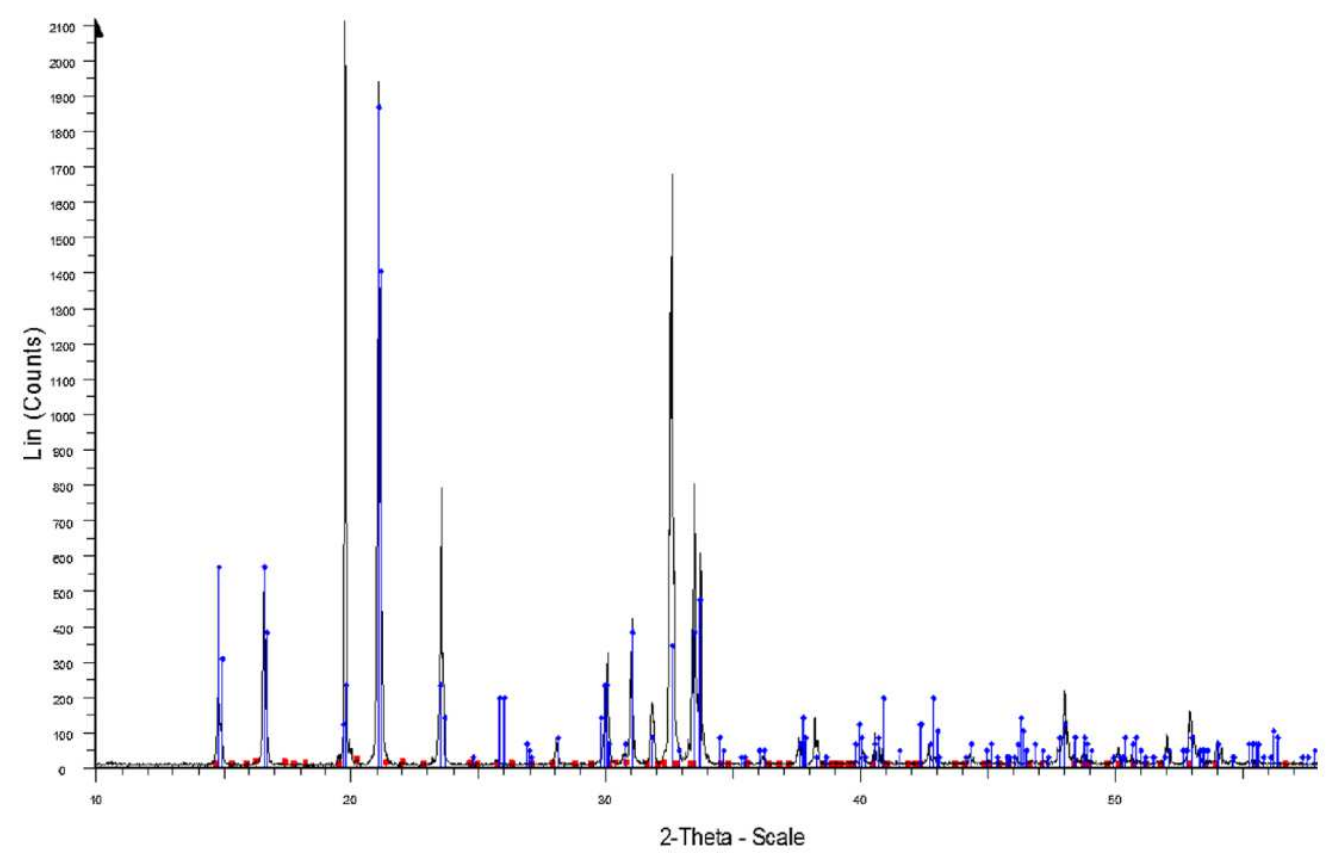

Fig. 4. XRD pattern of the commercial initial magnesium sulfate heptahydrate powder sample.

In Fig. 7 are reported the experimental diffraction patterns obtained for three samples S1, S2, S3 and S4. Sample S1 (blue spectrum) appears to be 18 well crystallized and only $\mathrm{MgSO}_{4} \cdot 7 \mathrm{H}_{2} \mathrm{O}$ phase is detected. This indicates that at $20^{\circ} \mathrm{C}$ under water vapor pressure of $25 \mathrm{hPa}$, the commercial powder is fully rehydrated into $\mathrm{MgSO}_{4} \cdot 7 \mathrm{H}_{2} \mathrm{O}$. Sample $\mathrm{S} 2$ (red spectrum) obtained at $40{ }^{\circ} \mathrm{C}$ and water vapor pressure of $25 \mathrm{hPa}$ is also well crystallized and corresponds to $\mathrm{MgSO}_{4} \cdot 6 \mathrm{H}_{2} \mathrm{O}$. No peak corresponding 
to the heptahydrate phase was detected. The mass loss between S1 and S2 conditions measured by TGA is equal to $7.2 \pm 0.3 \%$. Since the theoretical mass loss between heptahydrate and hexahydrate is equal to $7.3 \%$, these results indicate that the powder if fully dehydrated to $\mathrm{MgSO}_{4} \cdot 6 \mathrm{H}_{2} \mathrm{O}$ after 1 hour at $40{ }^{\circ} \mathrm{C}$ and water vapor pressure of $25 \mathrm{hPa}$ without further dehydration toward lower hydrate.

Nitrogen adsorption experiment on sample S2 leads to a type II adsorption isotherm according to the IUPAC classification [59] as shown in Fig. 5. This indicates that magnesium sulfate hexahydrate obtained by thermal dehydration of commercial magnesium sulfate heptahydrate presents neither micro nor mesopores but only macropores (pore diameter greater than $50 \mathrm{~nm}$ ). The Particle Size Distribution (PSD) of the same sample has been determined by means of laser granulometry. Fig. 6 shows the grain size distribution in the range between $1 \mu \mathrm{m}$ and $600 \mu \mathrm{m}$. The powder exhibits small particles of less than $10 \mu \mathrm{m}$ as well as large particles from $50 \mu \mathrm{m}$ to $600 \mu \mathrm{m}$ which can be explained by re-agglomeration phenomenon. The same results have been observed by scanning electron microscopy (Fig. 8) where large aggregates with a size of about few hundred micrometers have been observed.

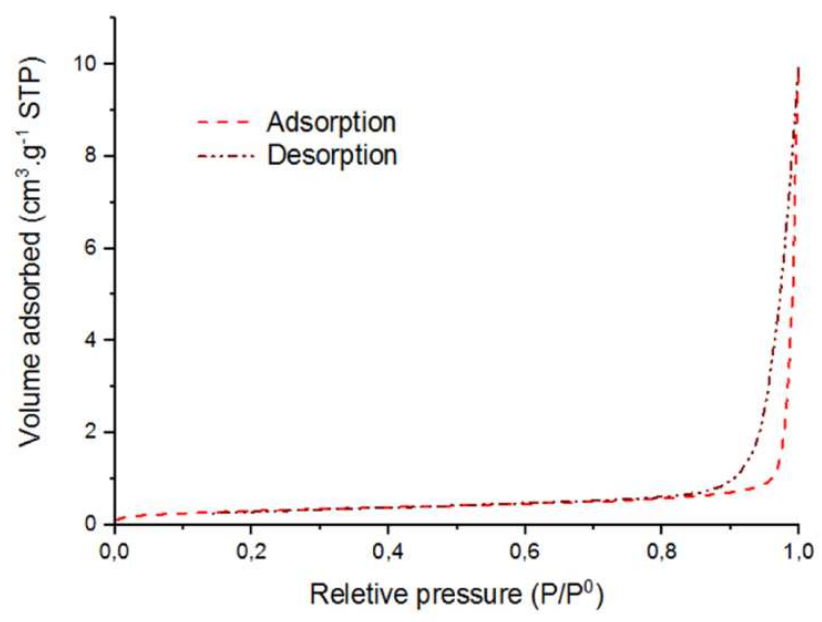

Fig. 5. Nitrogen adsorption-desorption isotherms of sample S2.

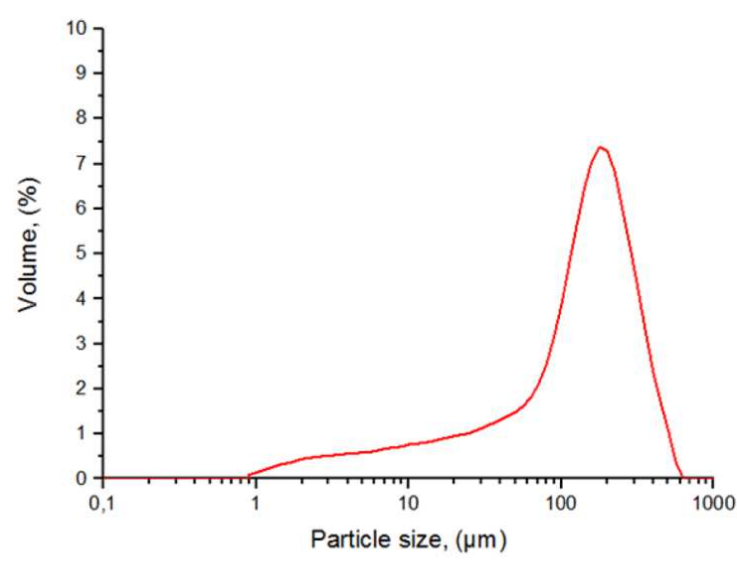

Fig. 6. Particle size distribution of sample S2.

All these characterizations allow to determine than the magnesium sulfate hexahydrate powder is constituted with grains of about $5 \mu \mathrm{m}$, without micro nor mesoporosity, and presents some aggregates of these dense grains. The nature of the $\mathrm{S} 2$ sample corresponding to magnesium sulfate hexahydrate is confirmed by the characterization of the sample S4. After 1 hour at $20^{\circ} \mathrm{C}$ under dry $\mathrm{N}_{2}$ 
atmosphere, the XRD pattern (black spectrum on Fig. 7) corresponds to anhydrous magnesium sulfate (compared to known pattern JCPDS 04-002-8228), and the mass loss between S2 and S4 conditions was measured to be $47.3 \pm 0.3 \%$ which is in very good agreement with the theoretical mass loss corresponding to the dehydration reaction of magnesium sulfate hexahydrate toward anhydrous magnesium sulfate (47.3\%).

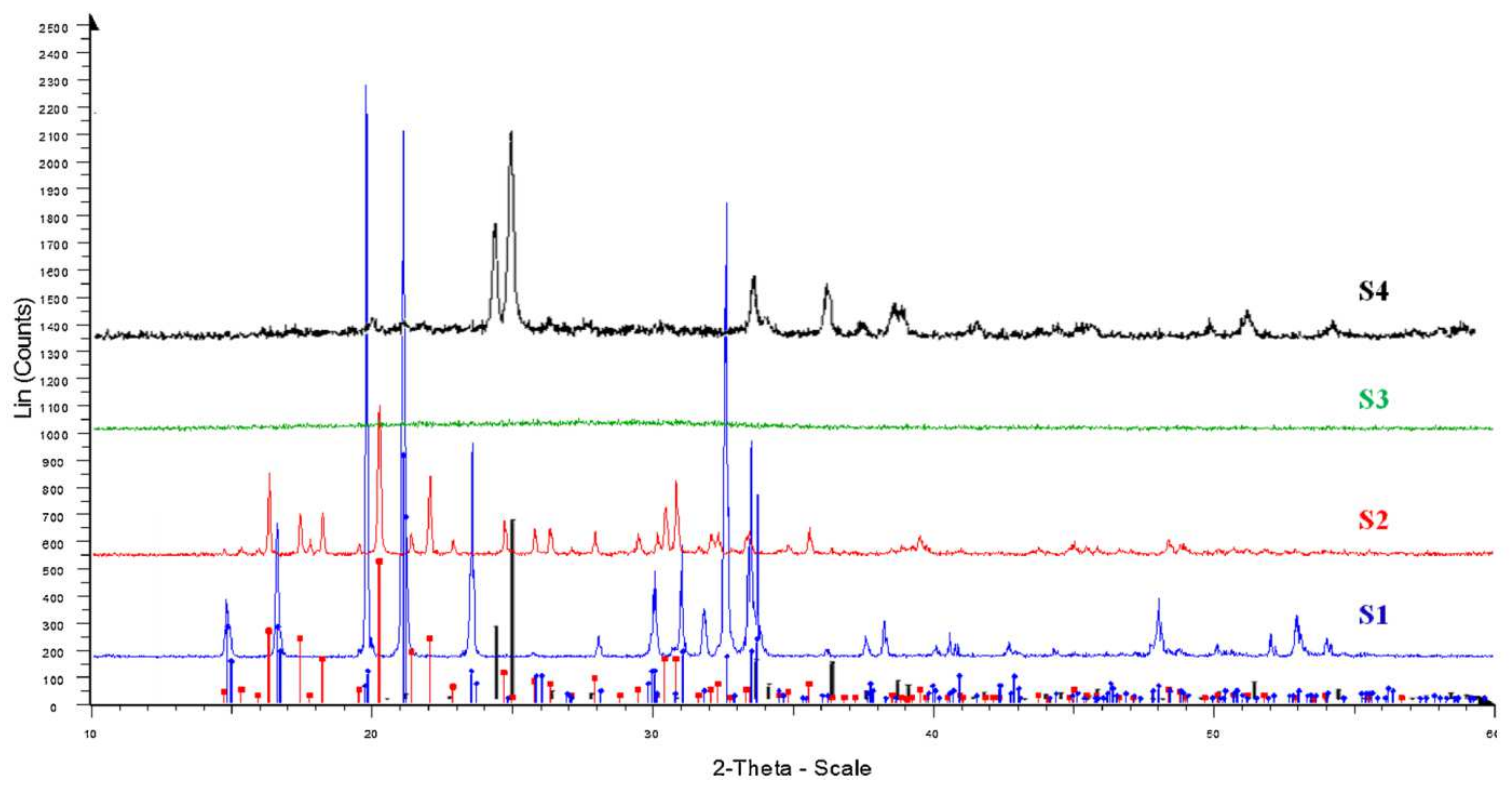

Fig. 7. X-ray diffraction patterns of the magnesium sulfate hydrate powders. The experimental spectra are compared with powder diffraction files for magnesium sulfate heptahydrate, magnesium sulfate hexahydrate and anhydrous magnesium sulfate (PDF no. 36-0419, 24-0719, 02-8228, JCPDS respectively.
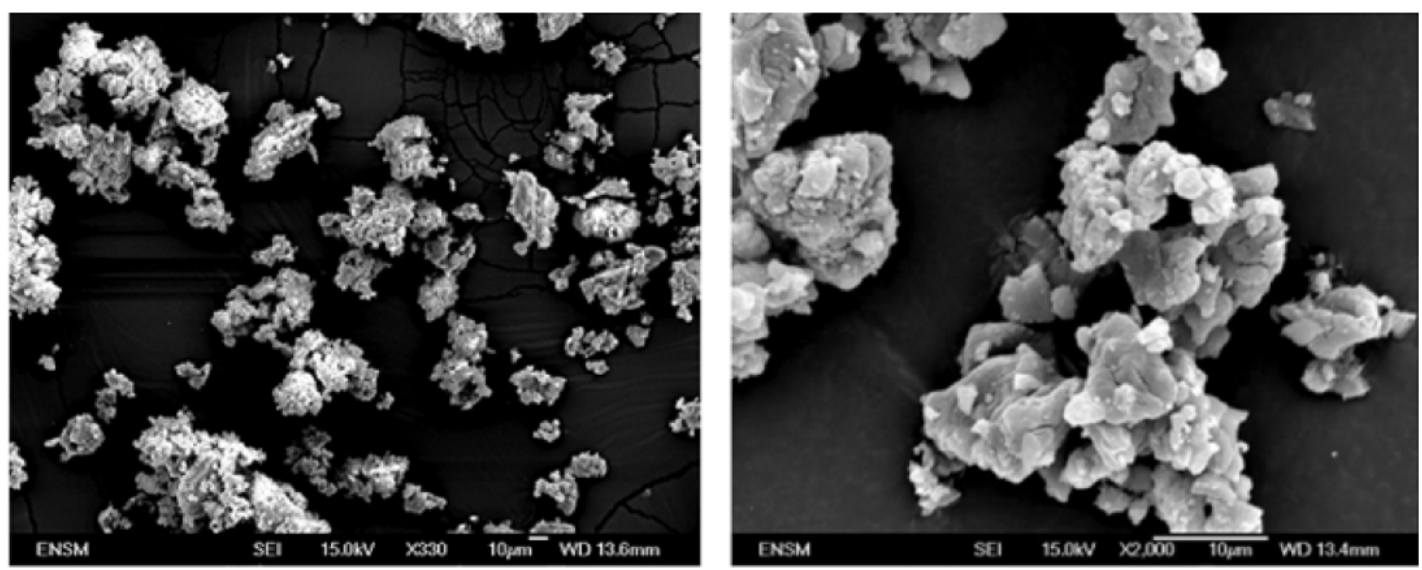

Fig. 8. SEM images of magnesium sulfate hexahydrate at $330 \times$ and $2000 \times$.

Finally the green diffraction pattern in Fig. 7 corresponds to the sample called S3 obtained at $40^{\circ} \mathrm{C}$ and $2 \mathrm{hPa}$ of water vapor pressure The formation of this amorphous phase is linked with the solid solution of water molecules in magnesium sulfate skeleton and is in agreement with results obtained in the literature $[12,60]$. The characterization of the thermal behavior of various magnesium sulfate hydrates indicates that heptahydrate is not stable at ambient conditions and that hexahydrate can be obtained in-situ at $40^{\circ} \mathrm{C}$ and with a water vapor pressure equal to $25 \mathrm{hPa}$. Other $\left(\mathrm{T}, \mathrm{P}_{\mathrm{H} 2 \mathrm{O}}\right)$ couples can be used to in-situ obtain $\mathrm{MgSO}_{4} \cdot 6 \mathrm{H}_{2} \mathrm{O}$ so that the starting solid phase, i.e. $\mathrm{MgSO}_{4} \cdot 6 \mathrm{H}_{2} \mathrm{O}$, for kinetic measurements in the next sections will be checked thank to the mass loss from $\mathrm{MgSO}_{4} \cdot 7 \mathrm{H}_{2} \mathrm{O}$. 


\subsection{Steady-state assumption}

According to Pijolat et al. [61], an experimental test consisting in comparing the kinetic rates measured by thermogravimetry and calorimetry allows to determine if a solid-gas reaction occurs in steady-state conditions or not. Indeed if the heat flux and the mass change rate are proportional during all the experiment, thus the assumption of steady-state is satisfied. A steady-state test was conducted at $40^{\circ} \mathrm{C}$ under water partial pressures of 5 and $7 \mathrm{hPa}$ by monitoring simultaneously the thermogravimetry and the heat flux signals. In Fig. 9a and $9 \mathrm{~b}$ are shown the heat flux and the mass change rate versus time for an experiment done at $40{ }^{\circ} \mathrm{C}$ under 5 and $7 \mathrm{hPa}$ of water vapor. The plot of the heat flux as a function of the mass change rate for the same experiment (Fig. 9c) does not give a straight line showing that the heat flux and the mass change rate are not proportional. Therefore, one can conclude that a steady-state assumption was not established and classical fractional conversion cannot be calculated from TG measurements.

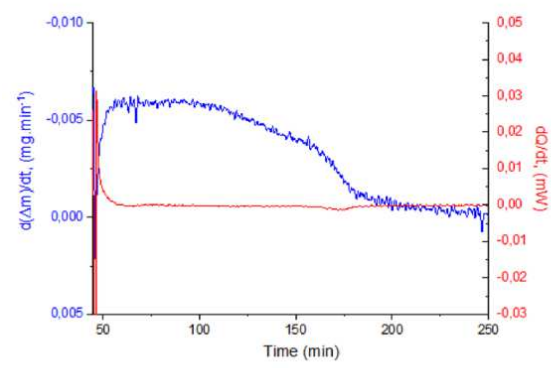

(a)

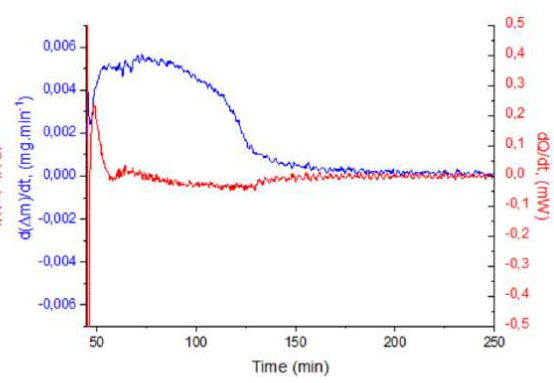

(b)

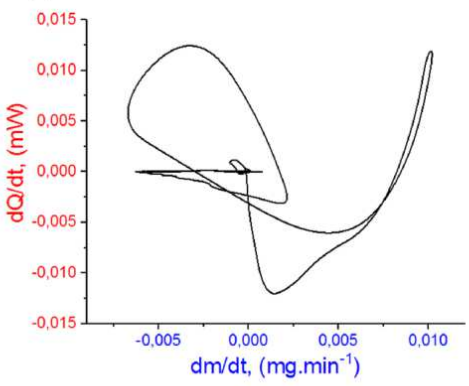

(c)

Fig. 9. Steady-state test for the dehydration of $\mathrm{MgSO}_{4} \cdot 6 \mathrm{H}_{2} \mathrm{O}$ : (a) heat flux and the mass change rate versus time at $5 \mathrm{hPa}$; (b) heat flux and the mass change rate versus time at $7 \mathrm{hPa}$; (c) heat flux versus the mass change rate.

\subsection{Influence of water vapor pressure}

Series of experiments have been performed in order to study the influence of the water vapor pressure on the kinetic of dehydration of magnesium sulfate hexahydrate. For all experiments, the temperature was fixed at $60^{\circ} \mathrm{C}$. Fig. 10 presents the curves of the fractional conversion and the mass loss rate curves $\mathrm{d}(\Delta \mathrm{m}) / \mathrm{dt}$ versus time for experiments conducted at water vapor pressure ranging from $2 \mathrm{hPa}$ to $50 \mathrm{hPa}$. The solid lines on the mass loss rate curves corresponds to isothermal and isobaric conditions, whereas the dashed lines correspond to the non-isobaric conditions, i.e. the period necessary to decrease the water vapor pressure from $100 \mathrm{hPa}$ to the desired value. This duration time is between 15 and 40 seconds depending on the desired water vapor pressure value (cf. zoomed images presented in Fig. 10b). These results show that increasing the water vapor 
pressure leads to a larger time to reach whole conversion indicating a decrease in the average reaction rate. However the influence of the water vapor pressure on the reaction rate at a given time appears more complex since an increase of water vapor partial pressure does not systematically lead to an increase in the rate of reaction whatever the time could be. Another particular feature is that the kinetic curves appears to be deceleratory $\alpha$-time curves for water vapor pressure between $2 \mathrm{hPa}$ and $21 \mathrm{hPa}$, corresponding to continuously decreasing mass loss rate curves. On the contrary at high water vapor pressure, i.e. $50 \mathrm{hPa}$, a change in the shape of the $\alpha$ time curve was found since an induction period was observed without any changes after the sample has reached the pre-determined reaction water vapor pressure and before the beginning of the mass-loss process. Once mass loss was initiated, the mass-loss rate gradually increased, reaching its maximum midway through the reaction, followed by gradual deceleration, this overall behavior being represented by the sigmoidal $\alpha$-time curve. Since low water vapor pressures are often used for heat storage application, only study at low water vapor pressure will be presented and discussed below.

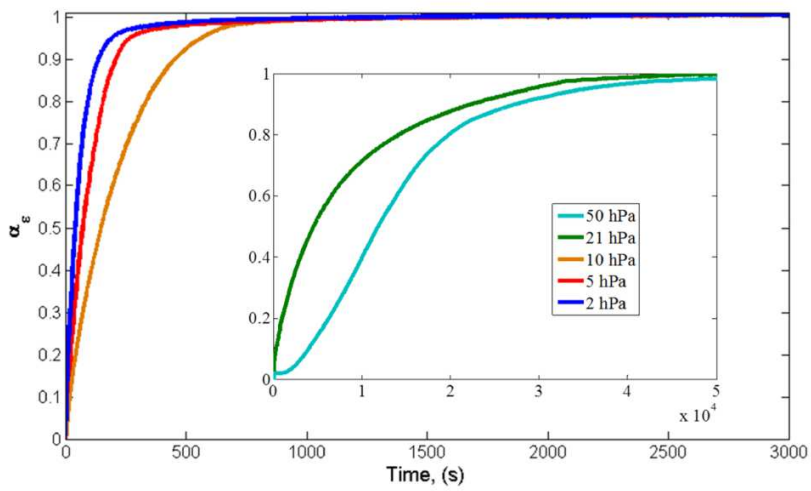

(a)

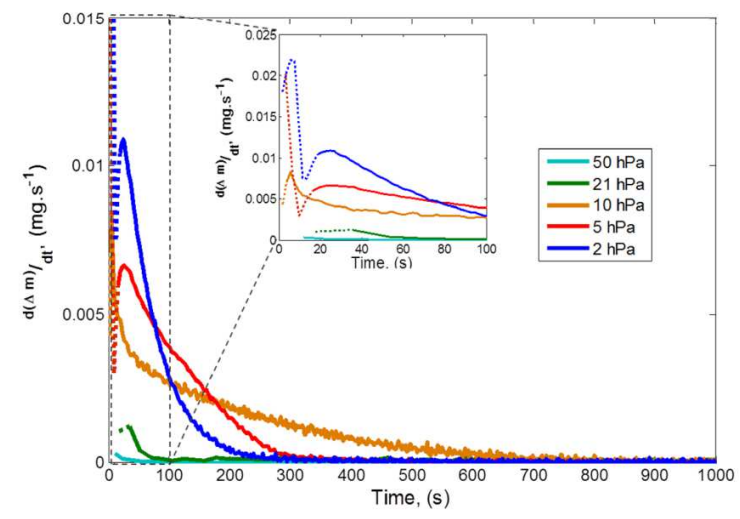

(b)

Fig. 10. Kinetic curves of sulfate magnesium hexahydrate dehydration versus time at $60^{\circ} \mathrm{C}$ : (a) $\alpha_{\varepsilon}(t)$ curves; (b) mass loss rate curves $d(\Delta m) / d t$

\subsection{Influence of temperature}

The experiments at various temperatures were performed in order to study the temperature influence on the reaction kinetic. Fig. 11 shows $\alpha_{\varepsilon}(t)$ curves and mass loss rate curves $d(\Delta m) / d t$ as a function of time obtained at various temperatures in the range $40^{\circ} \mathrm{C}-60^{\circ} \mathrm{C}$ for a given $2 \mathrm{hPa}$ water vapor pressure. As described in the previous section, the curves are continuously decreasing in isothermal and isobaric conditions (represented by the solid lines in Fig. 11). The time necessary to reach the completion of the reaction decreases when the temperature increases indicating an 
increase of the average reaction rate with the temperature; but as observed with the impact of the water vapor pressure, an increase of temperature does not systematically lead to an increase in the rate of reaction whatever the time could be.

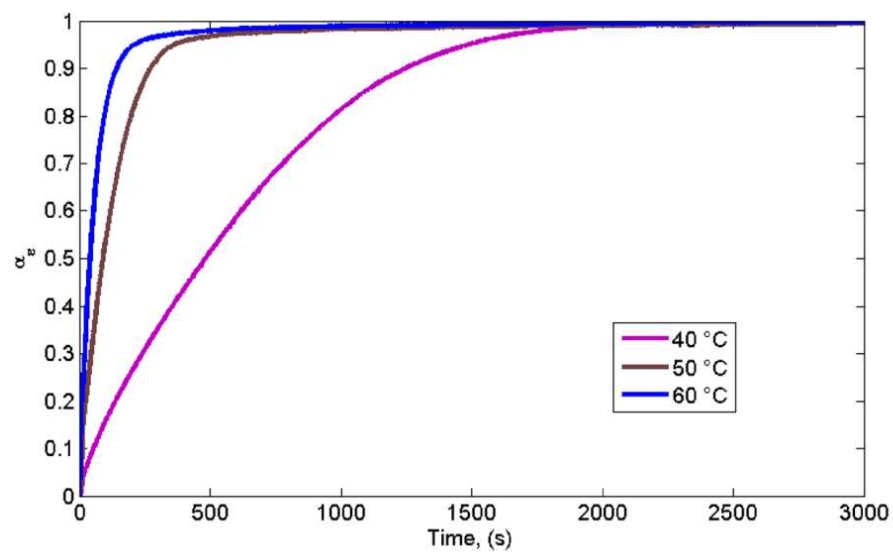

(a)

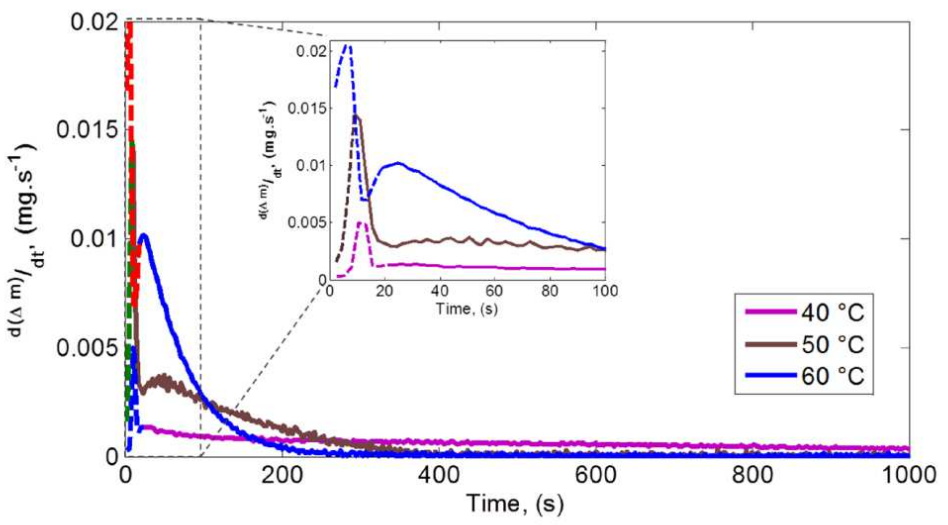

(b)

Fig. 11. Kinetic curves of sulfate magnesium hexahydrate dehydration versus time at $2 \mathrm{hPa}$ of water vapor pressure: (a) $\alpha \varepsilon(t)$ curves; (b) mass loss rate curves $d(\Delta m) / d t$.

\subsection{Kinetic modeling}

Fig. 12 shows the confrontation of the kinetic model to the experimental data obtained at $60{ }^{\circ} \mathrm{C}$ and under water vapor pressure of $2 \mathrm{hPa}$. The experimental $\alpha_{\varepsilon}(\mathrm{t})$ and $\mathrm{d}(\Delta \mathrm{m}) / \mathrm{dt}$ curves (round symbol) are superimposed to the calculated curves (solid lines). The values of parameters determined during this optimization procedure are given in Table 1. Parameters thus obtained show that the parameter $L$ is relatively small and approach to zero while the transfer coefficient $k_{\mathrm{H} 2 \mathrm{O}}$ is more important than the diffusion coefficient $D_{\text {Hго }}$. As it was discuss above, this results show that the diffusion of water molecules through a solid particle is fast and only the transfer of water molecules within thin fluid film at the surface is the rate-determining step. Thus the surface resistance control model is used for kinetic simulation with all the experimental conditions and the fraction conversion and mass loss rate are calculated using Eqs. (14) and (17) respectively. The experimental and simulated results are shown in Fig. 13 for experiments performed at $60^{\circ} \mathrm{C}$ and water vapor pressure of 2, 5, 10 and $21 \mathrm{hPa}$; and in Fig. 14 for experiments performed at $2 \mathrm{hPa}$ of water vapor pressure and temperature of 40, 
50 and $60^{\circ} \mathrm{C}$. Others experimental curves obtained for several temperature and water vapor pressure conditions are shown in Fig. 15 with the corresponding calculated curves. All these results show a good correlation between experimental and numerical data whatever the water vapor pressure and the temperature.

Table 1

Values of parameters determined during optimization procedure.

\begin{tabular}{lllll}
\hline$T\left({ }^{\circ} \mathrm{C}\right)$ & $P_{\mathrm{H}_{2} \mathrm{O}}(\mathrm{hPa})$ & $L$ & $k_{\mathrm{H}_{2} \mathrm{O}}\left(\mathrm{m} \mathrm{s}^{-1}\right)$ & $D_{\mathrm{H}_{2} \mathrm{O}}\left(\mathrm{m}^{2} \mathrm{~s}^{-1}\right)$ \\
\hline 60 & 2 & 0.005 & $7.7 \times 10^{-10}$ & $4 \times 10^{-13}$ \\
\hline
\end{tabular}

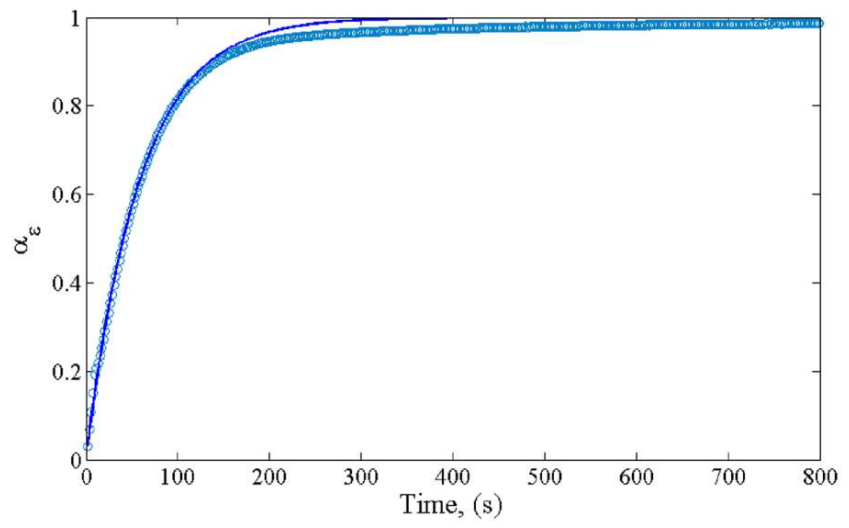

(a)

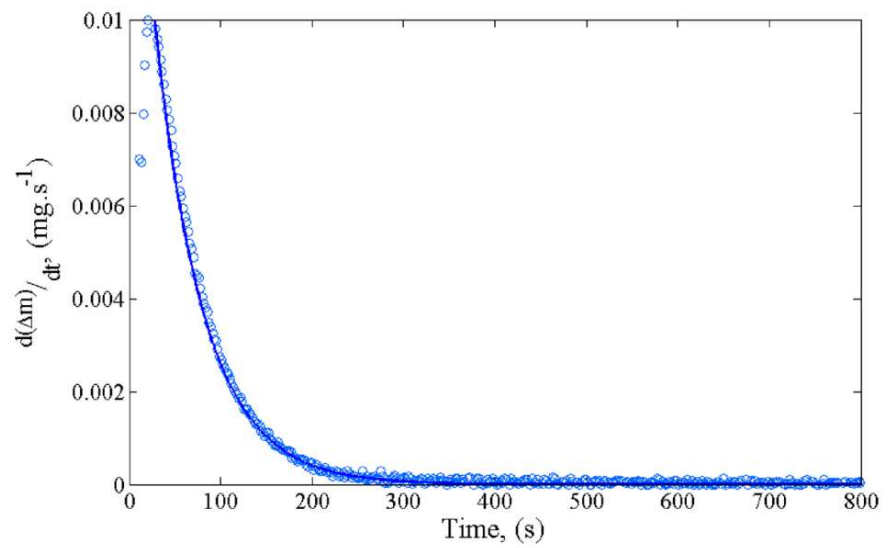

(b)

Fig. 12. Comparison between experimental and calculated kinetic curves obtained at $60{ }^{\circ} \mathrm{C}$ and $2 \mathrm{hPa}$ (a) $\alpha_{\varepsilon}(t)$ curves versus time; (b) mass loss rate curves $d(\Delta m) / d t$ versus time. 


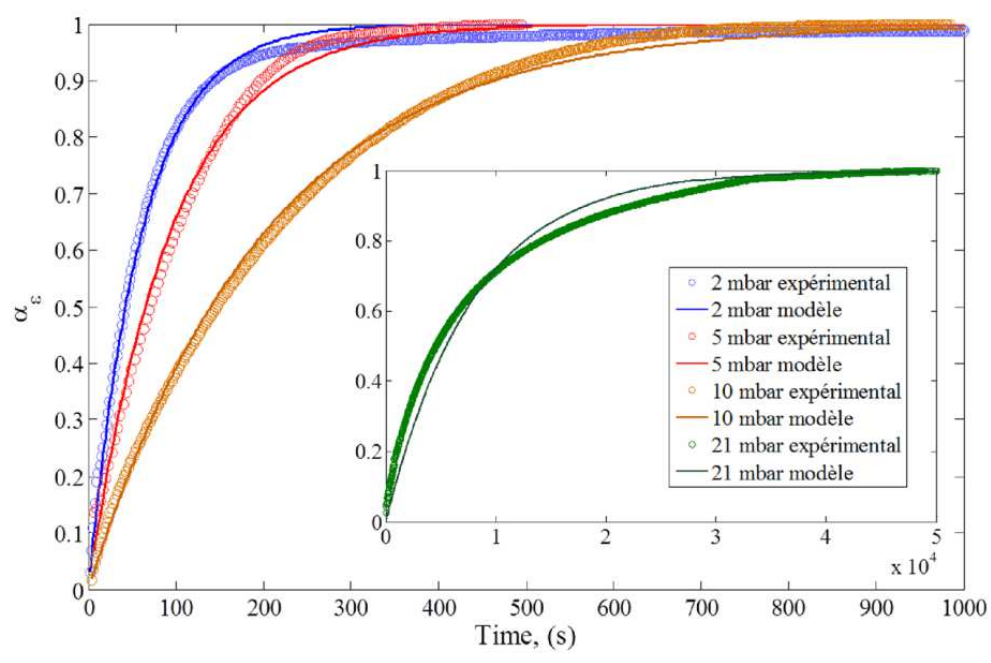

(a)

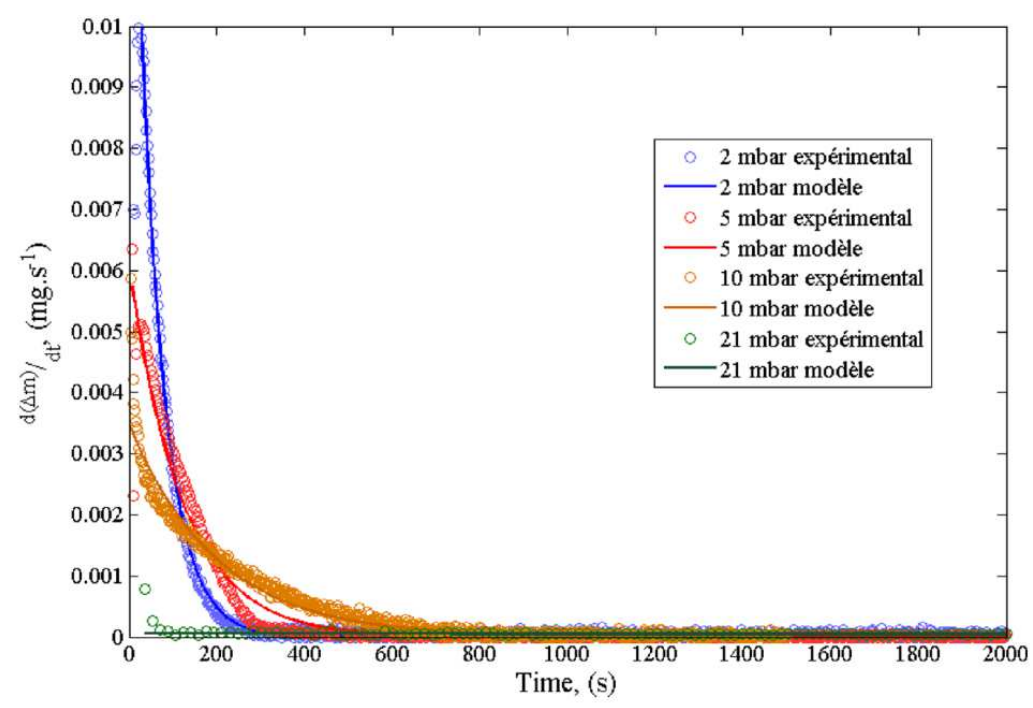

(b)

Fig. 13. Comparison between experimental and calculated kinetic curves obtained at $60^{\circ} \mathrm{C}$ and $2,5,10$ and 21 hPa: (a) $\alpha_{\varepsilon}(t)$ curves versus time; (b) mass loss rate curves $d(\Delta m) / d t$ versus time. 


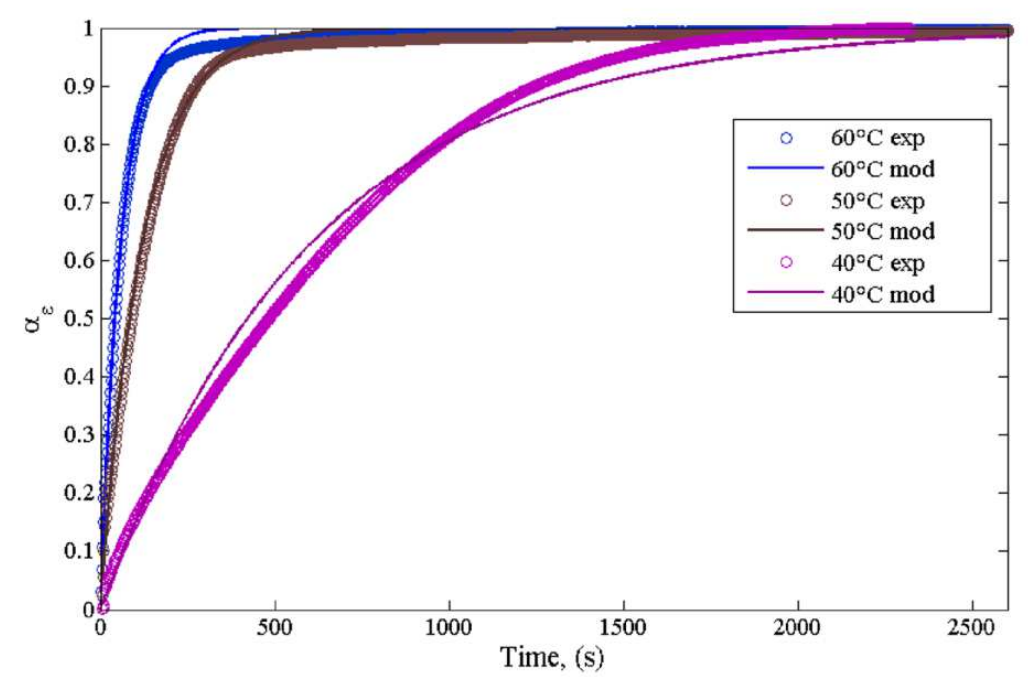

(a)

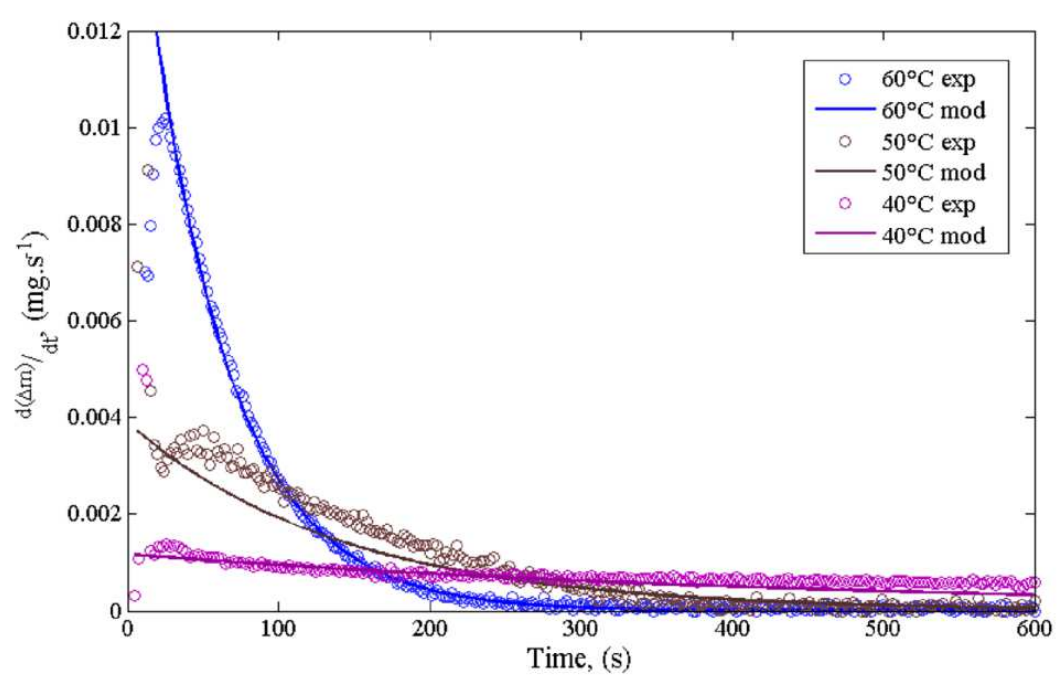

(b)

Fig. 14. Comparison between experimental and calculated kinetic curves obtained at $2 \mathrm{hPa}$ and 40,50 and $60^{\circ} \mathrm{C}$ : (a) $\alpha_{\varepsilon}(t)$ curves versus time; (b) mass loss rate curves $d(\Delta m) / d t$ versus time.

The values of fitted kinetic parameter obtained by simulation at different temperatures and water vapor pressures are summarized in Table 2 . These results show that the transfer coefficient $k_{\mathrm{H} 2 \mathrm{O}}$ increases with increasing the temperature and decreases with increasing the water vapor pressure. The values of the parameter $\mathrm{k}_{\mathrm{H} 2 \mathrm{O}}$ are plotted in Arrhenius coordinates in Fig. 16 for water vapor pressure of $2 \mathrm{hPa}$. The apparent activation energy $E_{A}$ is calculated from the slope value $\left(E_{A} / R T=-\right.$ 11360 ) and equal to $91.7 \mathrm{~kJ} \cdot \mathrm{mol}^{-1}$. The pre-exponential factor determined from the $y$-intercept is 8.9 $\times 10^{6} \mathrm{~m} \cdot \mathrm{s}^{-1}$. The values of the transfer coefficient $\left(\mathrm{k}_{\mathrm{H} 2 \mathrm{O}}\right)$ as a function of water vapor pressure at $60^{\circ} \mathrm{C}$ are plotted in Fig. 17. It is clear that $\mathrm{k}_{\mathrm{H} 2 \mathrm{O}}$ depends strongly on water vapor pressure: with the increase of the water vapor pressure the values of parameter $\mathrm{k}_{\text {H2O }}$ decrease. As it was defined above, $\mathrm{k}_{\mathrm{H} 2 \mathrm{O}}=\mathrm{D}^{*} / \delta$, where $D^{*}$ is the effective diffusive coefficient of water molecules and $\delta$ is the thickness of the transfer layer at the surface of the solid; in the case of the non-perfect solution, the dependence of the diffusion coefficient with the concentration of water inside the grain and the pressure of water vapor in the atmosphere at the surface (Eq. (7)) confirms the non-ideal behavior of 
the water molecules at the surface of the solid magnesium sulfate particle. Such a non-ideal behavior has been extensively studied and discussed in detail in the case of fluids confined in nanoporous materials [62-65]. In the present case, magnesium sulfate appears to be non-porous (or macroporous with pore diameter greater than $50 \mathrm{~nm}$ ), but it has been shown that water vapor molecules are in solid solution inside the magnesium sulfate skeleton for hydrates with a water content smaller than 6 water molecules per magnesium sulfate molecules. In consequence the origin of the non-ideality can be found in the interactions between water molecules and the magnesium sulfate skeleton near the surface in accordance with the strictly regular solid solution described in our previous work using a thermodynamic approach [28].

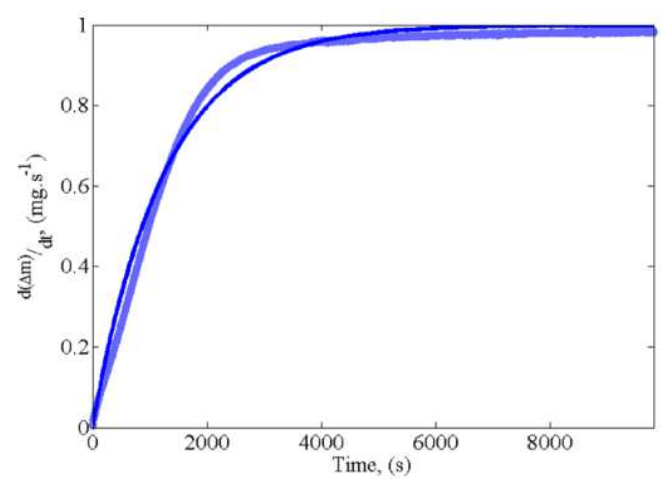

(a)

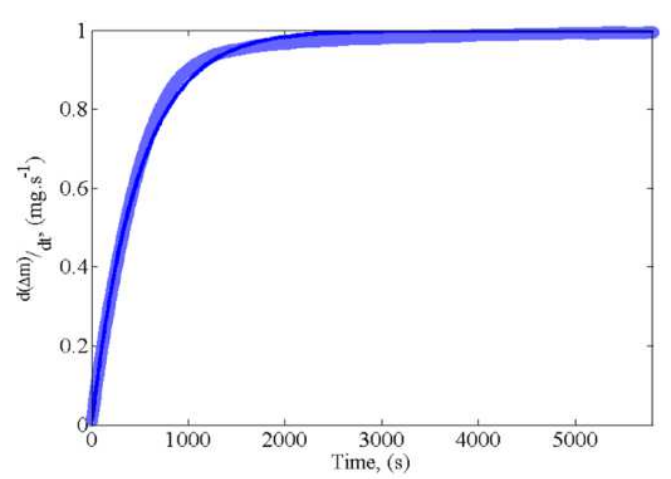

(c)

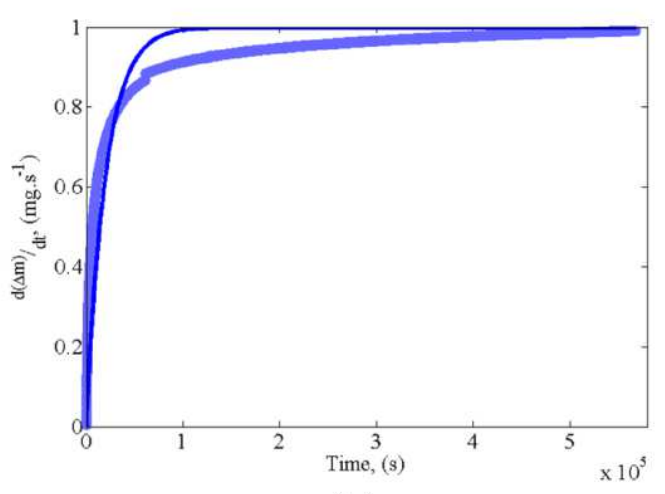

(b)

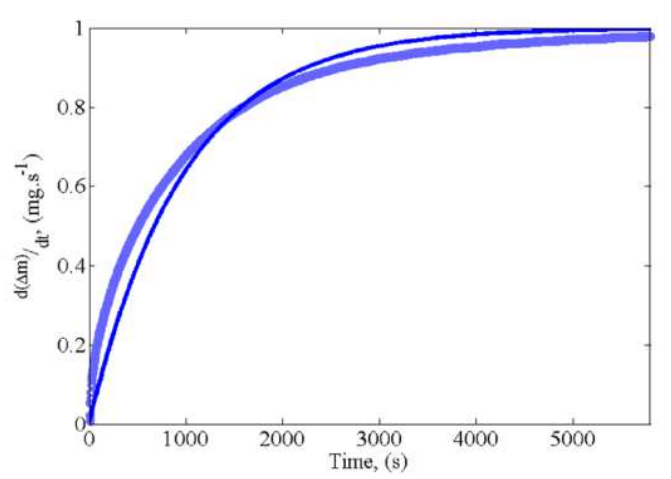

(d)

Fig. 15. Comparison between experimental (blue light curves) and calculated (blue dark curves) $\alpha_{\varepsilon}(t)$ curves obtained: (a) $2 \mathrm{hPa}$ and $35^{\circ} \mathrm{C}$; (b) $5 \mathrm{hPa}$ and $45^{\circ} \mathrm{C}$; (c) $5 \mathrm{hPa}$ and $50^{\circ} \mathrm{C}$; (d) $10 \mathrm{hPa}$ and $55^{\circ} \mathrm{C}$. 
Table 2

Values of kinetic parameter $k_{\mathrm{H}_{2} \mathrm{O}}$ determined during optimization procedure.

\begin{tabular}{llll}
\hline$T\left({ }^{\circ} \mathrm{C}\right)$ & $P_{\mathrm{H}_{2} \mathrm{O}}(\mathrm{hPa})$ & $k_{\mathrm{H}_{2} \mathrm{O}}\left(\mathrm{m} \mathrm{s}^{-1}\right)$ & Experience/model error \\
\hline 35 & 2 & $1.08 \times 10^{-10}$ & $2.1 \times 10^{-3}$ \\
40 & 2 & $1.38 \times 10^{-10}$ & $4.6 \times 10^{-3}$ \\
45 & 5 & $3.00 \times 10^{-12}$ & 0.25 \\
50 & 2 & $7.04 \times 10^{-10}$ & $8.5 \times 10^{-2}$ \\
50 & 5 & $3.05 \times 10^{-11}$ & $1.6 \times 10^{-3}$ \\
55 & 10 & $1.60 \times 10^{-12}$ & $3.1 \times 10^{-3}$ \\
60 & 2 & $1.45 \times 10^{-9}$ & 0.3 \\
60 & 5 & $7.10 \times 10^{-10}$ & $2.5 \times 10^{-3}$ \\
60 & 10 & $4.30 \times 10^{-10}$ & $2.0 \times 10^{-3}$ \\
60 & 21 & $9.00 \times 10^{-12}$ & 0.1 \\
\hline
\end{tabular}

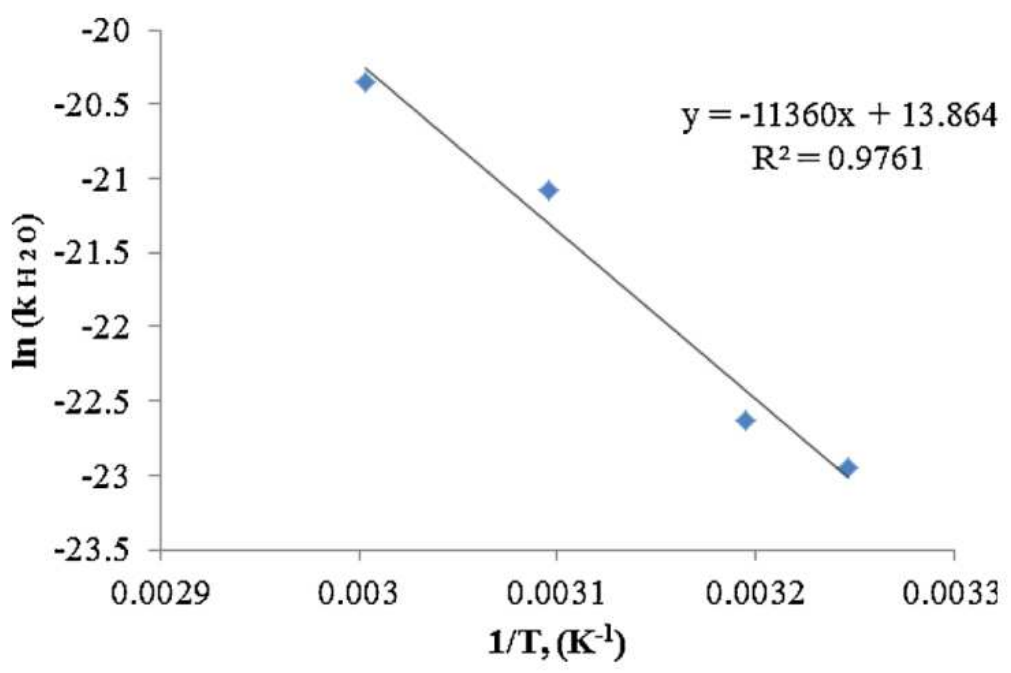

Fig. 16. Arrhenius plot of the transfer coefficient $k_{\mathrm{H}_{2} \mathrm{O}}$.

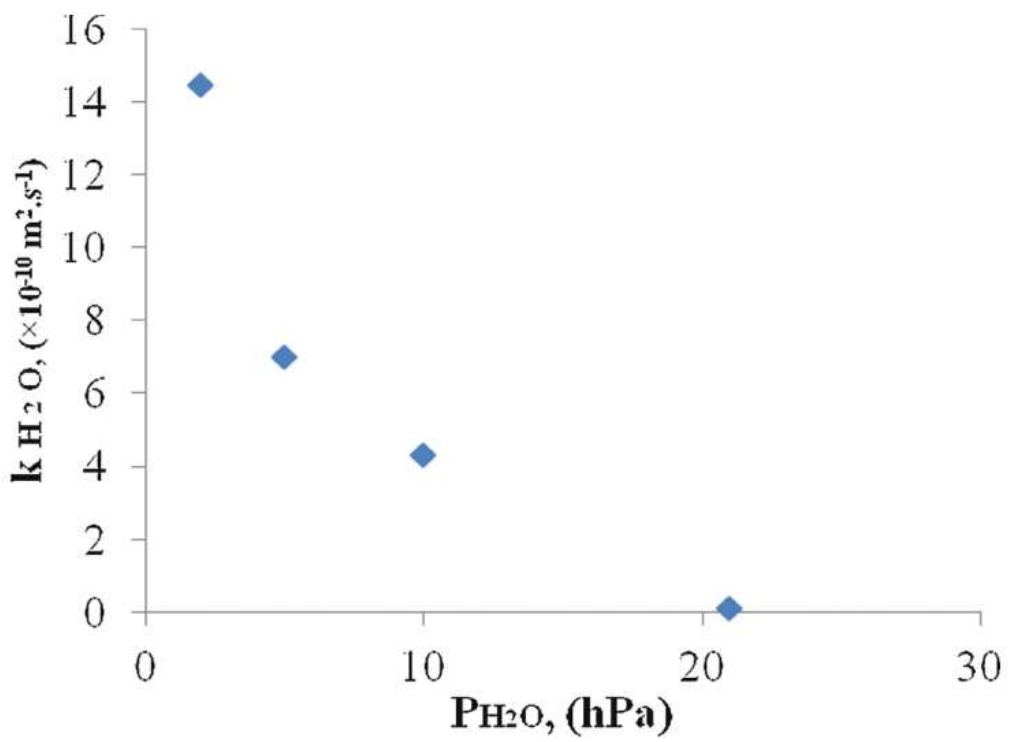

Fig. 17. Variation of transfer coefficient $k_{\mathrm{H} 2 \mathrm{O}}$ versus water vapor pressure at $60^{\circ} \mathrm{C}$ 


\section{Conclusions}

This work presents the detailed study of the dehydration reaction of magnesium sulfate hexahydrate conducted at the grain scale under isothermal and isobaric conditions, at low temperatures $\left(35^{\circ} \mathrm{C}\right.$ to $60{ }^{\circ} \mathrm{C}$ ) and low water vapor pressures $(2 \mathrm{hPa}$ to $21 \mathrm{hPa}$ ). A detailed mathematical model of diffusion of the water molecules in the solid solution to the surface followed by their transfer from the surface to the atmosphere has been proposed. The obtained results show that the influence of the transfer at the surface is higher while the diffusion step can be considered as negligible. The kinetic model of surface resistance has therefore been adopted and compared with experimental data. The curves calculated from this model show a good correlation with the experimental curves in the studied ranges of temperature and water vapor pressure. After fitting the model, the values of the transfer coefficient at surface $\mathrm{k}_{\mathrm{H} 2 \mathrm{O}}\left(\mathrm{m} \cdot \mathrm{s}^{-1}\right)$ were determined. The results show that the values of parameter $\mathrm{k}_{\text {H2O }}$ depend on both the temperature and the water vapor pressure. The transfer coefficient at the surface $\mathrm{k}_{\mathrm{H} 2 \mathrm{O}}$ was found to follow Arrhenius equation in the temperature range between 35 and $60{ }^{\circ} \mathrm{C}$ with an apparent activation energy $\mathrm{E}_{\mathrm{A}}$ equal to $91.7 \mathrm{~kJ} \cdot \mathrm{mol}^{-1}$. And it seems that the parameter $\mathrm{k}_{\text {н2О }}$ varies as the natural logarithm of water vapor pressure. This last dependence of the transfer coefficient is in agreement with a non-ideal behavior of the water molecules in the magnesium sulfate skeleton.

\section{Acknowledgement}

The authors acknowledge "ARC Energy" from Region AuvergneRhône-Alpes, France and French National Research Agency (ANR-16-CE22-0006-01) for the funding.

\section{References}

[1] T. Yan, T. Li, R. Wang, Advances in Solar Heating and Cooling, Elsevier, 2016.

[2] F. Kuznik, Chemisorption heat storage for solar low-energy buildings, Advances in Solar Heating and Cooling (2016) 467-489 (Chapter 17).

[3] T. Yan, R. Wang, T. Li, L. Wang, I. Fred, A review of promising candidate reactions for chemical heat storage, Renew. Sustain. Energy Rev. 43 (2015) 13-31.

[4] K. N'Tsoukpoe, H. Liu, N.L. Pierres, L. Luo, A review on long-term sorption solar energy storage, Renew. Sustain. Energy Rev. 13 (2009) 2385-2396.

[5] C. Bales, P. Gantenbein, A. Hauer, H. Henning, D. Jaenig, H. Kerskes, T. Nunez, K. Visscher, Thermal Properties of Materials for Thermo-chemical Storage of Solar Heat. A Report of IEA Solar Heating and Cooling programme - Task 32 "Advanced Storage Concepts for Solar and Low Energy Buildings" Report B2 of Subtask B, (2005).

[6] A. Sole, X. Fontanet, C. Barreneche, A. Fernandez, I. Martorell, L. Cabeza, Requirements to consider when choosing a thermochemical material for solar energy storage, Renew. Sustain. Energy Rev. 97 (2013) 1278-1286.

[7] K. Visscher, J. Veldhuis, Comparison of candidate materials for seasonal storage of solar heat through dynamic simulation of building and renewable energy system, Ninth International IBPSA Conference, Montreal, Canada, 2005.

[8] L. Scapino, H. Zondag, J.V. Bael, J. Diriken, C. Rindt, Sorption heat storage for longterm low-temperature applications: a review on the advancements at material and prototype scale, Appl. Energy 190 (2017) 920-948.

[9] N. Yu, R. Wang, L. Wang, Sorption thermal storage for solar energy, Prog. Energy Combust. Sci. 39 (2013) 489-514. 
[10] K. N'Tsoukpoe, T. Schmidt, H. Rammelberg, B. Watts, W. Ruck, A systematic multistep screening of numerous salt hydrates for low temperature thermochemical energy storage, Appl. Energy 124 (2014) 1-16.

[11] F. Kuznik, K. Johannes, C. Obrecht, Chemisorption heat storage in buildings: state of the art and outlook, Energy Build. 106 (2015) 183-191 SI: IEA-ECES Annex 31 Special Issue on Thermal Energy Storage.

[12] V. van Essen, H. Zondag, J. Gores, L. Bleijendaal, M. Bakker, R. Schuitema, W. van Helden, Z. He, C. Rindt, Characterization of $\mathrm{MgSO}_{4}$ hydrate for thermochemical seasonal heat storage, Environ. Earth Sci. 131 (2009) 41014.

[13] C. Ferchaud, H. Zondag, J. Veldhuis, R. de Boer, Study of the reversible water vapour sorption process of $\mathrm{MgSO}_{4} .7 \mathrm{H}_{2} \mathrm{O}$ and $\mathrm{MgCl}_{2} .6 \mathrm{H}_{2} \mathrm{O}$ under the conditions of seasonal solar heat storage, J. Phys.: Conf. Ser. 395 (2012).

[14] S. Hongois, F. Kuznik, P. Stevens, J. Roux, Development and characterisation of a new $\mathrm{MgSO}_{4}$-zeolite composite for long-term thermal energy storage, Sol. Energy Mater. Sol. Cells 95 (2011) 1831-1837.

[15] H. Zondag, Z.V. Essen, R. Schuitema, W.V. Helden, Characterisation of $\mathrm{MgSO}_{4}$ for thermochemical storage, Adv. Thermochem. Storage (2017).

[16] G. Whiting, D. Grondin, S. Bennici, A. Auroux, Heats of water sorption studies on zeolite- $\mathrm{MgSO}_{4}$ composites as potential thermochemical heat storage materials, Sol. Energy Mater. Sol. Cells 112 (2013) 112-119.

[17] V. Brancato, L. Calabrese, V. Palomba, A. Frazzica, M. Fullana-Puig, A. Solé, L. Cabeza, $\mathrm{MgSO}_{4} .7 \mathrm{H}_{2} \mathrm{O}$ filled macro cellular foams: an innovative composite sorbent for thermo-chemical energy storage applications for solar buildings, Sol. Energy 173 (2018) 1278-1286.

[18] D. Mahon, G. Claudio, P.C. Eames, An experimental investigation to assess the potential of using $\mathrm{MgSO}_{4}$ impregnation and $\mathrm{Mg}^{2+}$ ion exchange to enhance the performance of $13 \mathrm{X}$ molecular sieves for interseasonal domestic thermochemical energy storage, Energy Convers. Manag. 150 (2017) 870-877.

[19] S.Z. Xu, Lemington, R. Wang, L. Wang, J. Zhu, A zeolite 13X/magnesium sulfatewater sorption thermal energy storage device for domestic heating, Energy Convers. Manag. 171 (2018) 98-109.

[20] L. Calabrese, V. Brancato, V. Palomba, A. Frazzica, L.F. Cabeza, Assessment of the hydration/dehydration behaviour of $\mathrm{MgSO}_{4} .7 \mathrm{H}_{2} \mathrm{O}$ filled cellular foams for sorption storage applications through morphological and thermo-gravimetric analyses, Sustain. Mater. Technol. 17 (2018) 98-109.

[21] K. Posern, K. Linnow, M. Niermann, Ch. Kaps, M. Steiger, Thermochemical investigation of the water uptake behavior of $\mathrm{MgSO}_{4}$ hydrates in host materials with different pore size, Thermochim. Acta 611 (2015) 1-9.

[22] I. Glaznev, I. Ponomarenko, S. Kirik, Y. Aristov, Composites $\mathrm{CaCl}_{2} / \mathrm{SBA}-15$ for adsorptive transformation of low temperature heat: pore size effect, Int. J. Refrig. 34 (2011) 1244-1250.

[23] L.G. Gordeeva, A.D. Grekova, T.A. Krieger, Y.I. Aristov, Adsorption properties of composite materials (LiCl+LiBr)/silica, Microporous Mesoporous Mater. 126 (2009) 262-267.

[24] L.G. Gordeeva, I.S. Glaznev, E.V.S. nd, V.V. Malakhov, Y.I. Aristov, Impact of phase composition on water adsorption on inorganic hybrids salt/silica, J. Colloid. Interface Sci. 301 (2006) 685-691.

[25] A. Jabbari-Hichri, S. Bennici, A. Auroux, Enhancing the heat storage density of silica-alumina by addition of hygroscopic salts $\left(\mathrm{CaCl}_{2}, \mathrm{Ba}(\mathrm{OH})_{2}\right.$, and $\left.\mathrm{LiNO}_{3}\right)$, Sol, Energy Mater. Sol. Cells 140 (2015) 351-360.

[26] P. Donkers, S. Beckert, L. Pel, F. Stallmach, M. Steiger, O. Adan, Water transport in $\mathrm{MgSO}_{4} .7 \mathrm{H}_{2} \mathrm{O}$ during dehydration in view of thermal storage, J. Phys. Chem. C 119 (2015) 28711-28720.

[27] R. Ford, G. Frost, The low pressure dehydration of magnesium sulphate heptahydrate and cobaltous chloride hexahydrate, Can. J. Chem. (1956) 591-599.

[28] L. Okhrimenko, L. Favergeon, K. Johannes, F. Kuznik, M. Pijolat, Thermodynamic study of $\mathrm{MgSO}_{4}-\mathrm{H}_{2} \mathrm{O}$ system dehydration at low pressure in view of heat storage, Thermochim. Acta 656 (2017) 135-143. 
[29] H. Emons, G. Ziegenbalg, R. Naumann, F. Paulik, Thermal decomposition of the magnesium sulphate hydrates under quasi-isothermal and quasi-isobaric conditions, J. Therm. Anal. Calorim. (1982) 1463-1473.

[30] C. Ferchaud, Experimental Study of Salt Hydrates for Thermochemical Seasonal Heat (Ph.D. thesis), Technische Universiteit Eindhoven, 2016.

[31] S.J. Chipera, D.T. Vaniman, Experimental stability of magnesium sulfate hydrates that may be present on Mars, Geochim. Cosmochim. Acta 71 (2007) 241-250.

[32] A. Wang, J.J. Freeman, B.L. Jolliff, Phase transition pathways of the hydrates of magnesium sulfate in the temperature range $50 \mathrm{C}$ to $5 \mathrm{C}$ : implication for sulfates on mars, J. Geophys. Res. 114 (2006) E04010.

[33] I.-M. Chou, R.R. Seal, Magnesium and calcium sulfate stabilities and the water budget of mars, J. Geophys. Res. 112 (2007) E002898.

[34] M. Steiger, K. Linnow, D. Ehrhardt, M. Rohde, Decomposition reactions of magnesium sulfate hydrates and phase equilibria in the $\mathrm{MgSO}_{4}-\mathrm{H}_{2} \mathrm{O}$ and $\mathrm{Na}^{+}-\mathrm{Mg}^{2+}-\mathrm{Cl}^{-}-\mathrm{SO}_{4}{ }^{2-}-\mathrm{H}_{2} \mathrm{O}$ systems with implications for Mars, Geochim. Cosmochim. Acta 75 (2011) 3600-3626.

[35] K.-D. Grevel, J. Majzlan, Internally consistent thermodynamic data for magnesium sulfate hydrates, Geochim. Cosmochim. Acta 73 (2009) 6805-6815.

[36] K.-D. Grevel, J. Majzlan, A. Benisek, E. Dachs, M. Steiger, A. Fortes, B. Marler, Experimentally determined standard thermodynamic properties of synthetic $\mathrm{MgSO}_{4} \cdot 4 \mathrm{H}_{2} \mathrm{O}$ (starkeyite) and $\mathrm{MgSO}_{4} \cdot 3 \mathrm{H}_{2} \mathrm{O}$ : a revised internally consistent thermodynamic data set for magnesium sulfate hydrates, J. Geophys. Res. 12 (2012) 1042-1054.

[37] K. Posern, C. Kaps, Humidity controlled calorimetric investidation of the hydration of MgSO4 hydrates, J. Therm. Anal. Calorim. 92 (2008) 905-909.

[38] M. Steiger, K. Linnow, H. Juling, G. Gülker, A.E. Jarad, S. Brüggerhoff, D. Kirchner, Hydration of $\mathrm{MgSO}_{4} \cdot \mathrm{H}_{2} \mathrm{O}$ and generation of stress in porous materials, Cryst. Growth Des. 8 (2008) 336-343.

[39] C. Bales, P. Gantenbein, D. Jaenig, H. Kerskes, K. Summer, M. van Essen, Laborator Tests of Chemical Reactions and Prototype Sorption Storage Units. A Report of IEA Solar Heating and Cooling Programme, Task 32 Advanced Storage Concepts for Solar and Low Energy Buildings: Report B4 of Subtask B, (2008).

[40] M. Soustelle, Thermodynamic Modeling of Solid Phase, Wiley-ISTE, 2015.

[41] J.-R. Authelin, Thermodynamics of non-stoichiometric pharmaceutical hydrates, Int. J. Pharm. 303 (2005) $37-53$.

[42] F. Kang, F.G. Vogt, J. Brum, R. Forcino, R.C.B. Copley, G.W. Robert Carlton, Effect of particle size and morphology on the dehydration mechanism of a non-stoichiometric hydrate, Cryst. Growth Des. 12 (2012) 60-74.

[43] B.A.A. Balboul, Physicochemical characterization of the decomposition course of hydrated ytterbium nitrate: thermoanalytical studies, Thermochim. Acta 419 (2004) 173-179.

[44] G.N. Kustova, Y.A. Chesalov, Y.A. Chesalov, L.M. Plyasova, A. Nizovskii, Vibrational spectra of WO3.nH2O and WO3 polymorphs, Vibr. Spectrosc. 55 (2011) 235-240.

[45] G.J. Thorogood, B.J. Kennedy, V. Luca, Structure of the hydrated pyrochlore NaW2O6·nH2O, Physica B (2006) 9193.

[46] C. Ferchaud, R. Scherpenborg, H. Zondag, R. de Boer, Thermochemical seasonal solar heat storage in salt hydrates for residential applications - influence of the water vapor pressure on the desorption kinetics of $\mathrm{MgSO}_{4} .7 \mathrm{H}_{2} \mathrm{O}$, Energy Proc. 57 (2014) 2436-2440.

[47] P. Donkers, L. Pel, O. Adan, Experimental studies for the cyclability of salt hydrates for thermochemical heat storage, J. Energy Storage 5 (2016) 25-32.

[48] A.-J. de Jonga, L. van Vlieta, C. Hoegaertsa, M. Roelandsa, R. Cuypers, Thermochemical heat storage - from reaction storage density to system storage density, Energy Proc. 91 (2016) 128-137. 
[49] P. Pinel, C. Cruickshank, I. Beausoleil-Morrison, A. Wills, A review of available methods for seasonal storage of solar thermal energy in residential applications, Renew. Sustain. Energy Rev. 15 (2011) 3341-3359.

[50] S. Hasnain, Review on sustainable thermal energy storage technologies. Part I. Heat storage materials and techniques, Energy Convers. Manag. 39 (1998) 1127-1138.

[51] S. Vyazovkin, K. Chrissafis, M.D. Lorenzo, N. Koga, M. Pijola, B. Roduit, N. Sbirrazzuoli, J. Sunol, ICTAC Kinetics Committee recommendations for collecting experimental thermal analysis data for kinetic computations, Thermochim. Acta 590 (2017) 1-23.

[52] L. Favergeon, J. Morandini, M. Pijolat, M. Soustelle, A general approach for kinetic modeling of solid-gas reactions at reactor scale: application to kaolinite dehydroxylation, Oil Gas Sci. Technol. 68 (2013) 1039-1048.

[53] N. Koga, H. Tanaka, Effect of sample mass on the kinetics of thermal decomposition of a solid, J. Therm. Anal. 40 (1993) 1173-1179.

[54] L. Favergeon, M. Pijolat, Influence of water vapor pressure on the induction period during $\mathrm{Li}_{2} \mathrm{SO}_{4} \cdot \mathrm{H}_{2} \mathrm{O}$ single crystals dehydration, Thermochim. Acta 521 (2011) 155-160.

[55] O. Chaix-Pluchery, J.C. Mutin, J. Bouillot, J.C. Niepce, Neutron structure refinement of barium oxalate-oxalic acid dihydrate, $\mathrm{BaC}_{2} \mathrm{O}_{4} \cdot \mathrm{H}_{2} \mathrm{C}_{2} \mathrm{O}_{4} \cdot 2 \mathrm{H}_{2} \mathrm{O}$ and of related nonstoichiometric hydrates, Acta Cryst. 45 (1989) 1699-1705.

[56] E. Jeanneau, N. Audebrand, J. Auffredic, D. Louër, Crystal structure, thermal behaviour and zeolitic properties of $\mathrm{Cd}_{2} \mathrm{Zr}\left(\mathrm{C}_{2} \mathrm{O}_{4}\right)_{4} \cdot(4+n) \mathrm{H}_{2} \mathrm{O}$, J. Mater. Chem. 11 (2001) 2545-2552.

[57] J. Kärger, D.M. Ruthven, D.N. Theodorou, Diffusion in Nanoporous Materials, Wiley-VCH Verlag GmbH Co. KGaA, Weinheim, Germany, 2012.

[58] J. Crank, The Mathematics of Diffusion, Clarendon Press, Oxford, 1975.

[59] K.S.W. Sing, D.H. Everet, R.A.W. Haul, L. Moscou, R.A. Pierotti, J. Rouquerol, T. Siemieniewska, Reporting physisorption data for gas-solid systems with special reference to the determination of surface area and porosity, Pure Appl. Chem. 57 (1985) 603-619.

[60] C. Ferchaud, H. Zondag, R. de Boer, C. Rindt, Characterization of the sorption process in thermochemical materials for seasonal solar heat storage application, Proc. 12th Int. Conf. Energy Storage (2012) 16-18.

[61] M. Pijolat, M. Soustelle, Experimental tests to validate the rate-limiting step assumption used in the kinetic analysis of solid-state reactions, Thermochim. Acta. 478 (2008) 34-40.

[62] R. Krishna, Describing the diffusion of guest molecules inside porous structures, J. Phys. Chem. C 113 (2009) 1975619781.

[63] J. Kärger, D.M. Ruthven, Diffusion in nanoporous materials: fundamental principles, insights and challenges, N. J. Chem. 40 (2016) 4027-4048.

[64] J. Collell, G. Galliero, Determination of the thermodynamic correction factor of fluids confined in nano-metric slit pores from molecular simulations, J. Chem. Phys. 140 (2014) 194702-194708.

[65] A. Zhokh, Size-controlled non-fickian diffusion in a micro- and mesoporous material, Chem. Phys. 520 (2019) 27-31 